\title{
Modeled Antarctic Precipitation. Part I: Spatial and Temporal Variability*
}

\author{
David H. Bromwich AND Zhichang Guo ${ }^{+}$ \\ Polar Meteorology Group, Byrd Polar Research Center, and Atmospheric Sciences Program, Department of Geography, \\ The Ohio State University, Columbus, Ohio \\ LESHENG BAI AND QIU-SHI CHEN \\ Polar Meteorology Group, Byrd Polar Research Center, The Ohio State University, Columbus, Ohio
}

(Manuscript received 15 May 2002, in final form 17 March 2003)

\begin{abstract}
Surface snow accumulation is the primary mass input to the Antarctic ice sheets. As the dominant term among various components of surface snow accumulation (precipitation, sublimation/deposition, and snow drift), precipitation is of particular importance in helping to assess the mass balance of the Antarctic ice sheets and their contribution to global sea level change.

The Polar MM5, a mesoscale atmospheric model based on the fifth-generation Pennsylvania State UniversityNCAR Mesoscale Model, has been run for the period of July 1996 through June 1999 to evaluate the spatial and temporal variability of Antarctic precipitation. Drift snow effects on the redistribution of surface snow over Antarctica are also assessed with surface wind fields from Polar MM5 in this study. It is found that areas with large drift snow transport convergence and divergence are located around escarpment areas where there is considerable katabatic wind acceleration. It is also found that the drift snow transport generally diverges over most areas of East and West Antarctica with relatively small values.

The use of the dynamic retrieval method (DRM) to calculate precipitation has been developed and verified for the Greenland ice sheet. The DRM is also applied to retrieve the precipitation over Antarctica from 1979 to 1999 in this study. Most major features in the spatial distribution of Antarctic accumulation are well captured by the DRM results. In comparison with predicted precipitation amounts from atmospheric analyses and reanalyses, DRM calculations capture more mesoscale features of the precipitation distribution over Antarctica. A significant upward trend of +1.3 to $+1.7 \mathrm{~mm} \mathrm{yr}^{-2}$ for 1979-99 is found from DRM and forecast precipitation amounts for Antarctica that is consistent with results reported by other investigators and indicates that an additional $0.05 \mathrm{~mm} \mathrm{yr}^{-1}$ is being extracted from the global ocean and locked up in the Antarctic ice sheets. While there is good agreement in this trend among all of the datasets, the interannual variability about the trend on the continental scale is not well captured. However, on the subcontinental scale, the interannual variability about the trend is well resolved for sectors in West Antarctica and the South Atlantic. It is also noted that the precipitation trend is weakly downward over much of the continent.
\end{abstract}

\section{Introduction}

Surface snow accumulation is the primary mass input to the Antarctic ice sheets, and it has long been recognized as a potentially important contributor to global sea level change. Precipitation is the dominant term among various components of surface snow accumulation (precipitation, sublimation/vapor deposition, and snow drift) (Bromwich 1988) and its spatial and tem-

\footnotetext{
* Byrd Polar Research Center Contribution Number 1277.

+ Current affiliation: Center for Ocean-Land-Atmosphere Studies, Calverton, Maryland.
}

Corresponding author address: David H. Bromwich, Polar Meteorology Group, Byrd Polar Research Center, The Ohio State University, 1090 Carmack Road, Columbus, OH 43210.

E-mail: bromwich@polarmet1.mps.ohio-state.edu poral variability are necessary information to assess the surface mass balance. In the last three decades, three measurement methods have been used to estimate the precipitation and accumulation over the Antarctic ice sheets: direct measurements, remote sensing techniques, and glaciological approaches. No reliable dataset of snow accumulation and precipitation measurements over Antarctica for a long time period is available from these methods for the following reasons. First, the introduction of drift snow creates the problem of distinguishing snow that has been precipitated from what has been picked up by the wind and transported. As a result, snow collection gauges, which are commonly used in middle latitudes and alpine regions, are difficult to employ in the Antarctic, and the direct gauge measurements are not representative of either the local accumulation or the precipitation received. Other direct measurement techniques such as snow stakes, and acoustic depth 
gauges, are replete with practical difficulties. Second, satellite altimetry measurements (e.g., Wingham et al. 1998) give only the change in surface height. Densification of near-surface snow can decrease the surface height without any snow accumulation occurring, thus complicating the interpretation of surface height changes. For other remote sensing measurements, current retrieval algorithms such as the outgoing longwave radiation-based techniques used by Xie and Arkin (1998) do not work well at high latitudes where ice and snow on the surface affect the detection of new precipitation. Algorithms employing microwave emission characteristics (Winebrenner et al. 2001) and satellite radar scatterometer signatures (Drinkwater et al. 2001) to determine accumulation rates are promising, but are still in the early stages of development. Third, due to costs and logistic difficulties, ice core and snow pit data are collected in few locations over Antarctica, and thus the accumulation estimation from glaciological approaches lacks an adequate and uniform temporal resolution for large areas of the continent. As a result, only long-termaveraged continent-wide maps of snow accumulation (e.g., Vaughan et al. 1999) are presently available, with the interannual variability and trends measured for just a few locations (e.g., Mosley-Thompson et al. 1995).

Fortunately, the surface measurements derived from these methods are not the only source of information, and atmospheric techniques can be used for direct simulation or indirect determination of precipitation and/or accumulation with better temporal and spatial resolution. Three atmospheric methods are available to estimate net accumulation: moisture flux budget calculations, numerical modeling, and dynamic retrieval. The method of moisture flux budgets uses atmospheric moisture transport toward the continent to calculate the areaintegrated surface mass balance (Bromwich 1988, 1990). The spatial resolution of this approach is limited because the precipitation minus sublimation $(P-E)$ residual is the small net result of large moisture fluxes into and out of the region of interest. Cullather et al. (1998) used moisture flux calculations to evaluate spatial and temporal variability of Antarctic precipitation from the European Centre for Medium-Range Weather Forecasts (ECMWF) operational analyses for 1985-94.

Atmospheric models can also be used to simulate various physical processes related to the Antarctic atmospheric circulation and to calculate the surface mass balance, which is determined by these processes. This method not only can provide information on the spatial and temporal distribution of the surface mass balance, but also can be used to gain insight into the mechanisms that cause mass balance variations and response to climate change. The advantage of using this approach is that the surface mass balance is obtained at high spatial resolution. Model output can be used to complement sparse measurements. In addition, the results might help to explain the observed surface mass balance distribution. The spatial and temporal variability of net snow accumulation over Antarctica from the ECMWF Reanalysis (ERA-15, 1979-93) have been presented by Turner et al. (1999). Genthon and Krinner (2001) compared net precipitation (precipitation minus sublimation) simulations from seven different general circulation models (GCMs) with the observation-based accumulation compilation from Vaughan et al. (1999), and summarized systematic biases present in those models.

The third atmospheric method, called "dynamic retrieval" uses the dynamic association among meteorological variables to retrieve precipitation values. Chen et al. (1997b) and Bromwich et al. (2001b) developed this method to derive the precipitation over Greenland from a vertical motion calculation, and it has proved to be a relatively economical method to retrieve the snow accumulation over Greenland with good spatial and temporal resolution. In comparison to atmospheric models, the dynamic retrieval method (DRM) has the advantage that no initialization and parameterization of complex physical processes are necessary in the retrieval process, and associated errors in parameterizations and model spinup are reduced. These advantages make the retrieval method attractive.

In this study, the precipitation for Antarctica from 1979 to 1999 has been retrieved by the DRM using ECMWF Tropical Ocean Global Atmosphere (TOGA) analyses (ECT) and ERA-15. Additionally, the Polar MM5, a regional atmospheric model based on the fifthgeneration Pennsylvania State University-National Center for Atmospheric Research (PSU-NCAR) Mesoscale Model (MM5; Bromwich et al. 2001a; Cassano et al. 2001; Guo 2002; Guo et al. 2003), has been run over Antarctica for July 1996-June 1999, and the simulated precipitation is compared with the DRM precipitation. Also, to examine the spatial and temporal variability of modern precipitation over Antarctica, DRMderived precipitation data are contrasted with simulated precipitation from ERA-15, ECT, and the National Centers for Environmental Prediction-Department of Energy (NCEP-DOE) Atmospheric Model Intercomparison Project-2 (AMIP-2) Reanalysis (NCEP2). This study is intended to demonstrate the reliability of the dynamic retrieval method and evaluate its ability in representing the spatial and temporal variability of Antarctic precipitation in comparison with Polar MM5 simulations and global analyses products. A comparison study evaluates the variability of West Antarctic precipitation with respect to the El Niño-Southern Oscillation (ENSO; Guo et al. 2004, hereafter GBH).

\section{Methodology}

In this section, a brief introduction is given on each of the methods used to evaluate precipitation: the DRM, Polar MM5, and atmospheric analyses and reanalyses data archives. 


\section{a. Dynamic retrieval method}

A natural method for retrieving precipitation from the observed wind, temperature, geopotential height, and moisture fields is using an atmospheric model and a four-dimensional data assimilation (FDDA) system. Both NCEP and ECMWF analyses and reanalyses projects have produced global analyses of atmospheric fields, which includes the global recovery of precipitation. However, as complex parameterizations of physical processes are involved in atmospheric modeling and FDDA, the spatial resolution of the precipitation derived by the above reanalyses is low, and FDDA systems at high resolution are very computationally demanding. Bromwich et al. (1993) use a statistical diagnostic approach to calculate precipitation over Greenland from the advection of relative geostrophic vorticity at the 500$\mathrm{hPa}$ level. Chen et al. (1997b) and Bromwich et al. (2001b) extend this work by using a generalized vertical motion equation to calculate precipitation, and the method can be used over mountainous regions with steep slopes, such as Greenland and Antarctica. As stated above, this method has the advantage that no initialization and parameterization of complex physical processes are necessary in the retrieval process.

Vertical motion can be calculated from geopotential height, temperature, and wind fields in global analyses and reanalyses data. The topographic effects on precipitation and atmospheric motion are greatly influenced by the computational accuracy of the horizontal pressure gradient force over mountainous regions (Colle et al. 1999), especially near the steep slopes of mountains and ice sheets. In order to improve the estimation of precipitation over steep slopes, the equivalent geopotential and geostreamfunction in $\sigma$ coordinates are used in the generalized $\omega$ equation (Chen et al. 1997a; Bromwich et al. 2001b).

The equivalent geopotential height $\phi_{e}$ is derived from the solution of the following equation (Chen and Bromwich 1999):

$\nabla^{2} \phi_{e}=\nabla^{2} \phi+\frac{\partial}{\partial x}\left(R T \frac{\partial \ln p_{*}}{\partial x}\right)+\frac{\partial}{\partial y}\left(R T \frac{\partial \ln p_{*}}{\partial y}\right)$,

where $\phi, T$, and $p_{*}$ are geopotential height, temperature, and surface pressure in $\sigma$ coordinates, respectively, and $R$ is the gas constant for dry air.

If the model equation is solved in a limited region, the equivalent isobaric geopotential, and geopotential in $\sigma$ coordinates can be separated into its inner part $\phi_{e i}, \phi_{i}$ and harmonic part $\phi_{e h}, \phi_{h}$ (Chen and Kuo 1992) as

$$
\phi_{e}=\phi_{e h}+\phi_{e i}, \quad \phi=\phi_{h}+\phi_{i} \text {. }
$$

Based on (1), the inner part of the equivalent isobaric geopotential height in $\sigma$ coordinates $\phi_{e i}$ can be derived from the solution of the following Poisson equation: $\nabla^{2} \phi_{e i}=\nabla^{2} \phi_{i}+\frac{\partial}{\partial x}\left(R T \frac{\partial \ln p_{*}}{\partial x}\right)+\frac{\partial}{\partial y}\left(R T \frac{\partial \ln p_{*}}{\partial y}\right)$

with zero Dirichlet boundary value.

The vorticity and divergence equations can be transformed into the equations of the inner parts of the streamfunction and velocity potential, respectively, and they are expressed by

$$
\begin{aligned}
& \frac{\partial \psi_{i}}{\partial t}+f_{0} \chi_{i}=\psi_{\mathrm{adv}, i}, \\
& \frac{\partial \chi_{i}}{\partial t}+\phi_{\text {eia }}=\chi_{\mathrm{adv}, i}-E_{i},
\end{aligned}
$$

where $E_{i}=m^{2}\left(U^{2}+V^{2}\right)_{i} / 2 ; \psi_{i}$ and $\chi_{i}$ are inner parts of the streamfunction and velocity potential, respectively; the terms $\psi_{\mathrm{adv}, i}$ and $\chi_{\mathrm{adv}, i}$ are the variation rates of the inner parts of the streamfunction and velocity potential caused by advection; and $m$ is the map scale factor.

The inner part of the ageostrophic geopotential $\phi_{\text {eia }}$ (the difference between $\phi_{e i}$ and geostrophic geopotential $\phi_{\text {eig }}=f_{0} \psi_{i}$ ) can be written as (Chen et al. 1997a)

$$
\begin{aligned}
& \frac{\partial \phi_{e i a}}{\partial t}+m_{0}^{2} \mathbf{A} \nabla^{2} \chi_{i}-f_{0}^{2} \chi_{i} \\
& \quad=\phi_{e, \text { had }, i}-f_{0} \psi_{\text {adv }, i}+m_{0}^{2} \mathbf{A} D_{h},
\end{aligned}
$$

where $m_{0}$ is the average value of the map scale factor in the integration region: $\phi_{e, \text { had }, i}$ is the variation rate of the geopotential caused by advection and diabatic heating, and $\mathbf{A}$ is a matrix comprised of $T$ and $\sigma$ with units of $\mathrm{J} \mathrm{kg}^{-1}$ (Chen et al. 1997a). Here

$$
D_{h}=D-D_{i} \text {, }
$$

where $D_{i}$ and $D_{h}$ are the inner and harmonic parts of the divergence, respectively (Chen and Kuo 1992).

If the tendency of ageostrophic geopotential in (6) is neglected, this approximation is referred to as a balanced ageostrophic approximation (Chen et al. 1996). Thus, Eq. (6) becomes

$$
m_{0}^{2} \mathbf{A} \nabla^{2} \chi_{i}-f_{0}^{2} \chi_{i}=\phi_{e, \mathrm{had}, i}-f_{0} \psi_{\mathrm{adv}, i}+m_{0}^{2} \mathbf{A} D_{h} .
$$

Equation (8) is a velocity potential form of the generalized $\omega$ equation for the balanced ageostrophic approximation in $\sigma$ coordinates. In this equation, the diabatic and advection terms computed by the ageostrophic wind are the same as those in the generalized $\omega$ equation in $p$ coordinates (Pauley and Nieman 1992), but the effect of orography on the vertical motion is much better described than that in $p$ coordinates. If Eq. (8) is transformed into $p$ coordinates and the term $\phi_{e, \text { had, } i a}$ is computed by the geostrophic wind and expressed by $\phi_{e, \text { had }, i a, g}$, Eq. (8) becomes a velocity potential form of the quasigeostrophic $\omega$ equation. In order to reduce computational errors in the solution of (8), a harmonic-sine spectral method (Chen and Kuo 1992) is used. It is seen from the above that the equivalent geopotential is used 
to develop a generalized $\omega$ equation in $\sigma$ coordinates, and this equation can be used to improve $\omega$ calculation over mountainous regions.

Using the continuity equation and vertical finite differencing, the pressure vertical velocity $\omega$ in $\sigma$ coordinates can be calculated by

$$
\frac{\omega}{p}=m_{0}^{2}(\mathbf{I}-\mathbf{C})\left(\frac{u}{m_{0}} \frac{\partial \ln p_{*}}{\partial x}+\frac{v}{m_{0}} \frac{\partial \ln p_{*}}{\partial y}\right)-m_{0}^{2} \mathbf{C} \nabla^{2} \chi_{i},
$$

where $\mathbf{I}$ is a unit matrix, $\mathbf{C}$ is a lower-triangular matrix comprised of $\sigma$ and its vertical difference (Chen et al. 1997a), and $u, v$ are the horizontal wind components; $\chi_{i}$ is derived from Eq. (8).

Only large-scale condensation is considered (Haltiner and Williams 1980, p. 309) in computing precipitation. The condensation rate can be expressed by

$$
\frac{d q_{s}}{d t}=\delta q_{s} T\left(\frac{L R-C_{p} R_{v} T}{C_{p} R_{v} T^{2}+q_{s} L^{2}}\right) \frac{\omega}{p},
$$

where condensation from saturated air is denoted by $d q_{s} / d t, q_{s}$ is the saturation specific humidity, $L$ is the latent heat of condensation, $C_{p}$ is the specific heat of the air at constant pressure, and $R_{v}$ is the gas constant for moist air. The Kronecker delta $\delta$ is used to indicate the assumption that the condensation begins at some critical relative humidity $r_{c}$ when upward vertical motion is present; $r_{c}$ is a tunable parameter in the model. In this paper, the critical relative humidity $r_{c}$ is assumed to be $94 \%$ based upon model tests over the Antarctic continent with different $r_{c}$ values (the value was found to be relatively insensitive to elevation). It is noteworthy that precipitation over the Southern Ocean is underestimated by using this $r_{c}$ value although the temporal variability is well captured, as discussed below.

If all of the condensate from saturated expansion is assumed to fall instantly as precipitation, the precipitation per unit area can be calculated from vertical integration of condensation rate $d q_{s} / d t$. The precipitation is calculated twice per day based on the ECT at 0000 and 1200 UTC for 1985-99 and four times a day based on ERA-15 at 0000, 0600, 1200, and 1800 UTC for the years 1979-93. The retrieved precipitation is produced from the DRM with ECMWF reanalysis (1979-90) and operational analyses (1991-99). The annual precipitation is derived by adding daily precipitation amounts for the whole year. In this paper, $22 \sigma$ levels at $\sigma=$ $0.995,0.980,0.955,0.920,0.875,0.820,0.750,0.670$, $0.590,0.505,0.420,0.340,0.270,0.220,0.180,0.140$, $0.110,0.090,0.070,0.050,0.030$, and 0.010 are used in the vertical, and a $40-\mathrm{km}$ grid size is used in the horizontal. The square model domain used in this study consists of 181 grid points in each orthogonal direction, centered at the South Pole, with a horizontal polar stereographic projection resolution of $40 \mathrm{~km}$ (Fig. 1). The model topography data over the Antarctic continent are also interpolated from a modern $5-\mathrm{km}$ resolution digital elevation model (DEM) of Antarctica (Liu et al. 1999) using bilinear interpolation from the nearest points.

\section{b. Polar MM5}

The Polar MM5 model is a regional atmospheric model based on the PSU-NCAR MM5 (Grell et al. 1994), and has been adapted specifically for ice sheet environments by the Polar Meteorology Group of the Byrd Polar Research Center at The Ohio State University (Bromwich et al. 2001a; Cassano et al. 2001). This model is being used at two locations to produce real-time mesoscale and synoptic forecasts in the Antarctic (model output is available online at http://www.mmm.ucar. edu/rt/mm5/amps/ and http://polarmet.mps.ohio-state. edu/PolarMet/antarcticnwp.html), and it has proved to be skillful in simulating the atmospheric circulation over polar regions (Cassano et al. 2001; Bromwich et al. 2001a; Guo 2002; Guo et al. 2003). Given the skill present in Polar MM5 simulations over polar ice sheets, the model output can be used to study the precipitation and accumulation over Antarctica. Polar MM5 is based on version 2 of the PSU-NCAR MM5. A general description of version 2 of MM5 is given by Dudhia (1993) and Grell et al. (1994). The model configuration used for the simulations and the changes made to the standard version of MM5 for use in polar regions are described below.

For the Polar MM5 simulations moist physics are solved with the explicit cloud and precipitation prediction scheme (Dudhia 1993; Grell et al. 1994). The Reisner explicit microphysics parameterization (Reisner et al. 1998) is used to represent the resolvable scale cloud and precipitation processes, and the Grell parameterization (Grell et al. 1994) is used to represent the subgridscale cloud processes. In order to eliminate the cloudy bias in polar simulations with MM5 the equation for ice nuclei concentration from Meyers et al. (1992) was used to replace the Fletcher (1962) equation in the explicit microphysics parameterization.

The transfer of shortwave and longwave radiation through the atmosphere is predicted with a modified version of the NCAR Community Climate Model, version 2 (CCM2), radiation parameterization (Hack et al. 1993). For the Polar MM5 simulations, the cloud ice water (CIW) path and its radiative effects are included in the modified CCM2 radiation parameterization, and predicted cloud water and ice mixing ratios from the Reisner explicit microphysics parameterization are used to determine the radiative properties of the modeled cloud cover.

Turbulent fluxes in the atmosphere, and the turbulent fluxes between the atmosphere and the surface, are parameterized using the 1.5-order turbulence closure parameterization used in the NCEP Eta Model (Janjić 1994). Heat transfer through the model substrate (i.e., snow and ice) is predicted using a multiplayer "soil" model. The thermal properties used in the soil model 


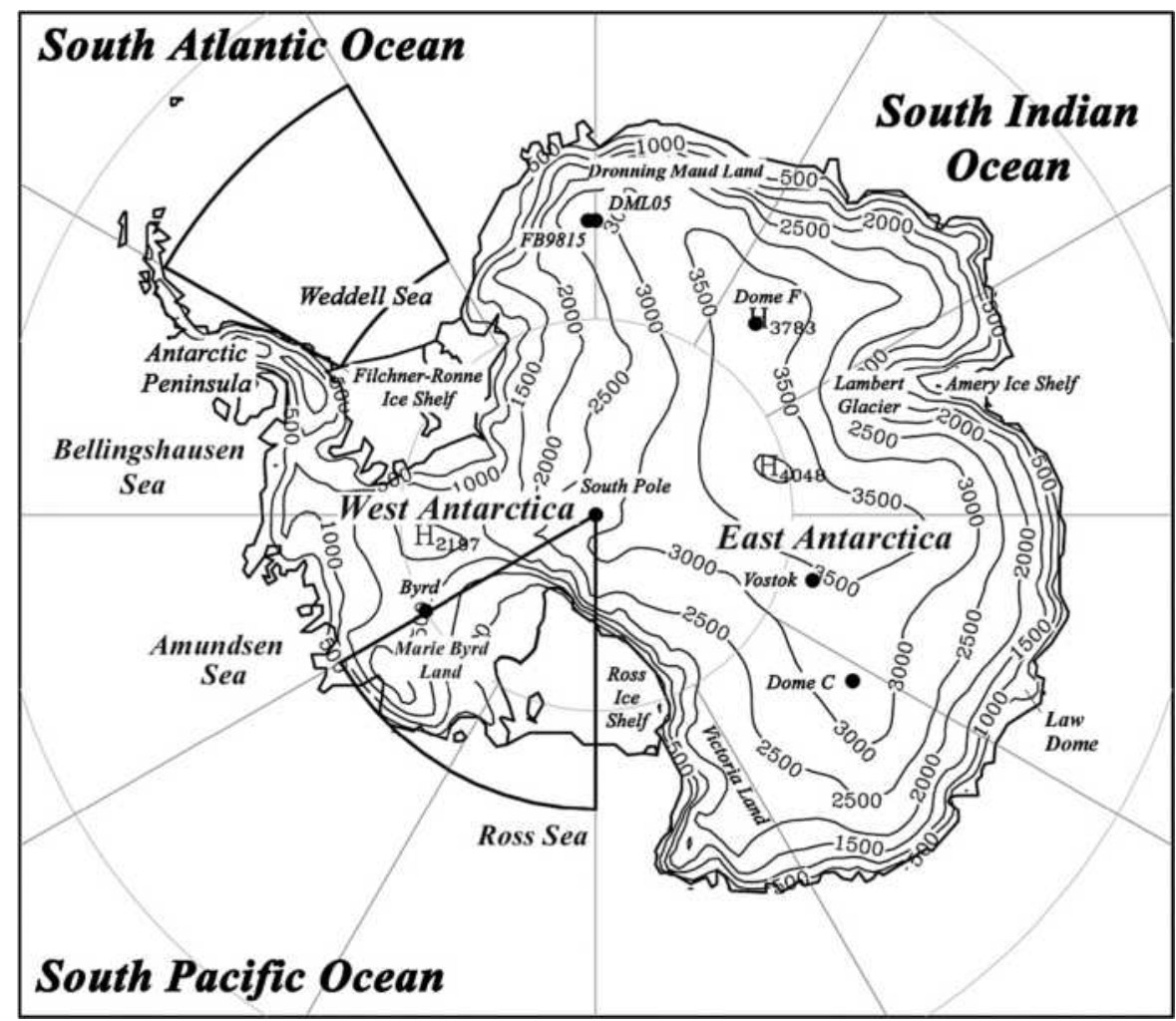

FIG. 1. Antarctica with topographic features and West Antarctic sectors that are of particular interest. The dots indicate the locations of stations used in this study. Elevation contour interval is $500 \mathrm{~m}$.

for snow and ice surface types are modified following Yen (1981). In addition the number of substrate levels represented in the soil model is increased from six to eight, with an increase in the resolved substrate depth from 0.47 to $1.91 \mathrm{~m}$. Also, a sea ice surface type is added to the 13 surface types available in the standard version of MM5 (Hines et al. 1997). The sea ice surface type allows for fractional sea ice cover in any oceanic grid point, with surface fluxes within the sea ice grid points calculated separately for the open water and sea ice portions of the grid point. These fluxes are then averaged before interacting with the overlying atmosphere. The sea ice thickness varies from 0.2 to $0.95 \mathrm{~m}$ and is dependent on the hemisphere and sea ice fraction at the grid point.

The square model domain used in this study consists of 120 grid points in each direction, centered at the South Pole, with a horizontal resolution of $60 \mathrm{~km}$. The top pressure is set at $10 \mathrm{hPa}$, and a rigid-lid upper boundary condition is used in the simulations. A total of 32 $\sigma$ sigma levels are used in the vertical, of which 7 are located within the lowest $400 \mathrm{~m}$ of the atmosphere. The lowest sigma level is located at a nominal height of 12 $\mathrm{m}$ above ground level (AGL). This relatively high resolution near the surface is required to accurately represent the evolution of the shallow katabatic layer over the Antarctic ice sheet. The model topography data over the Antarctic continent are also interpolated from the 5$\mathrm{km}$ resolution DEM data of Antarctica (Liu et al. 1999). The areas for Filchner-Ronne Ice Shelf and Ross Ice Shelf are manually identified from climatic maps. The surface height and land-use type for both ice shelves are set at $50 \mathrm{~m}$ and permanent ice with constant albedo of 0.80 , respectively.

The $2.5^{\circ}$ horizontal resolution ECMWF TOGA surface and upper-air operational analyses are used to provide the initial and boundary conditions for the model atmosphere. These data are interpolated to the Polar MM5 model grid using the standard preprocessing programs provided by NCAR for use with the MM5 modeling system. In addition the $1.125^{\circ}$ ECMWF TOGA global surface analyses are used to specify the initial surface temperature (and sea surface temperature) and model substrate soil temperature. The daily polar gridded sea ice concentration data with $25-\mathrm{km}$ horizontal resolution obtained from the National Snow and Ice Data Center are used to identify the sea ice surface type and its fractional coverage at each model grid.

The Polar MM5 is used to produce short duration (36 h) simulations of the atmospheric state over Antarctica from July 1996 through June 1999. This 36-month period had two well-defined cold events with positive Southern Oscillation index (SOI) values in 1996 and $1998 / 99$ and a warm event with negative SOI values in 


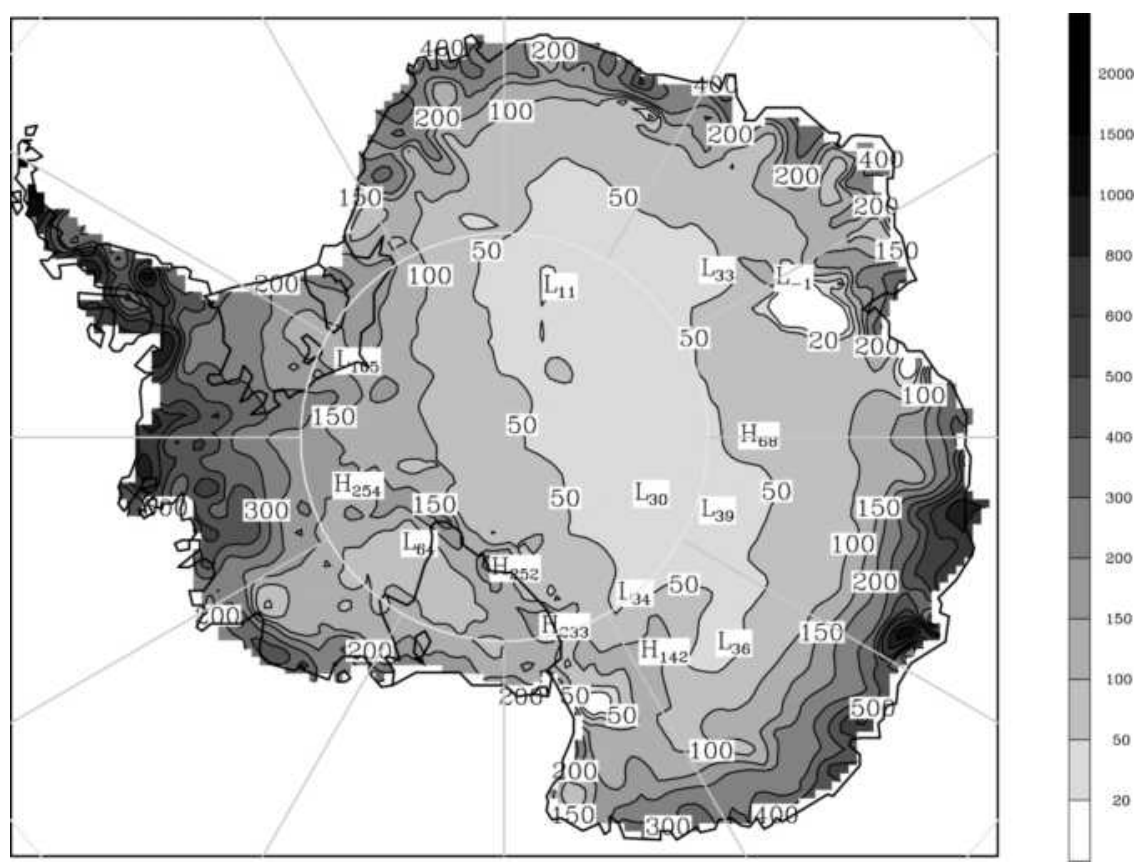

Fig. 2. Vaughan et al. (1999) long-term accumulation distribution ( $\mathrm{mm} \mathrm{yr}^{-1}$ water equivalent).

1997/98, and was selected to capture the temporal variability of Antarctic precipitation over an entire ENSO cycle. The model is initialized with the 0000 UTC ECMWF analyses for each preceding day, with the 12$36-h$ forecasts used for data analyses. Using the 12-36$\mathrm{h}$ forecasts allows for model "spin up" to resolve inconsistencies in the initial conditions. The $12-36-\mathrm{h}$ period is chosen based on recent unpublished validations of Polar MM5 performance, which show small changes in rms errors of upper-level relative humidity between 12 and $36 \mathrm{~h}$. However, it is noted that inconsistencies may arise in the moisture fields due to the frequent reinitializations.

\section{c. Atmospheric analysis and reanalyses}

Short-term precipitation forecasts from three numerical analysis and reanalysis data archives are used to depict spatial and temporal variability of Antarctic precipitation in this study. Two of the archives consist of ECMWF (ERA-15) and NCEP2 reanalyses, which span 1979-93 and 1979-99, respectively, and are available at 6 -h intervals on a $2.5^{\circ} \times 2.5^{\circ}$ grid. The third dataset is the ECMWF operational analysis, for which daily forecast precipitation is only available after 1991 on a roughly $1.25^{\circ} \times 1.25^{\circ}$ grid. Due to the data absence before 1991, ECMWF forecast precipitation is obtained from a combination of the ERA-15 reanalysis (197990) and ECMWF operational analysis (1991-99). It is noted that there are some concerns with the ERA-15 (Bromwich et al. 2000) and NCEP2 (Hines et al. 2000) reanalyses.

\section{The spatial distribution of Antarctic precipitation}

The most reliable source for identifying the spatial distribution of Antarctic precipitation comes from the long-term annual accumulation depiction synthesized from glaciological data. Figure 2 shows the most recent accumulation compilation over the Antarctic ice sheets from Vaughan et al. (1999). The surface snow accumulation is the net result of snowfall, sublimation/deposition, drift snow effects, and runoff, and its primary components are precipitation and sublimation. In this section, the annual precipitation minus sublimation simulated by the Polar MM5 is first compared with the accumulation analysis of Vaughan et al. (1999). With the surface wind fields from the model output, the impact of drift snow redistribution on snow accumulation is also assessed. Based on the good performance of Polar MM5 in representing $P-E$ fields, all precipitation fields from DRM, NCEP2, and ECT are then compared with that simulated by Polar MM5.

Figure 3 shows the annual precipitation minus sublimation simulated by the Polar MM5. Sublimation is derived from the simulated latent heat flux. Compared to the accumulation analysis of Vaughan et al. (1999) all major features are reproduced by the Polar MM5. Both maps show large values along the coast of East and West Antarctica, and over the Antarctic Peninsula, and small amounts over the plateau of East Antarctica and around the Ross and Filchner/Ronne Ice Shelves, and Lambert Glacier. The spatial distribution of the model predicted $P-E$ distribution is in good qualitative 


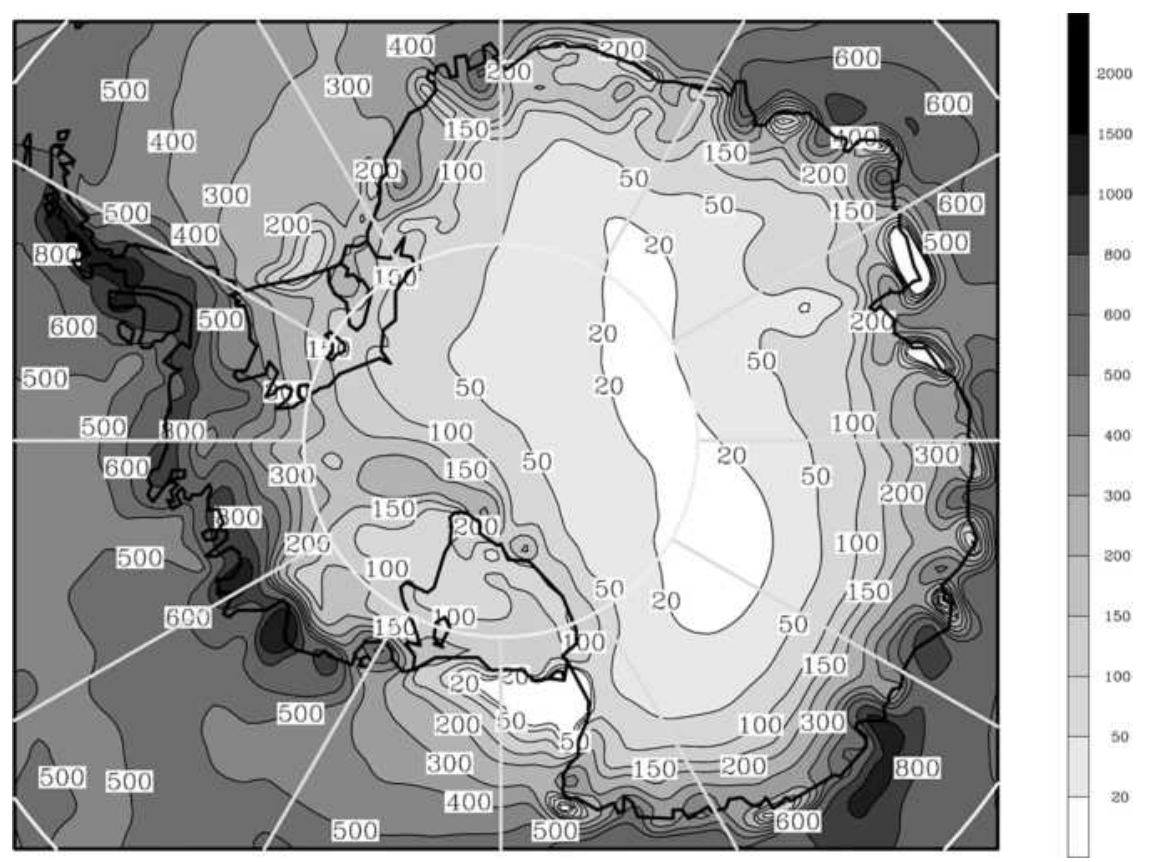

FIG. 3. Annual precipitation minus sublimation for Jul 1996-Jun 1999 simulated by Polar MM5 ( $\mathrm{mm} \mathrm{yr}^{-1}$ water equivalent).

agreement with the accumulation analysis of Vaughan et al. (1999). Additionally, minimum values around Dronning Maud Land, Victoria Land, and Marie Byrd Land, and maximum values over the Antarctic Peninsula, southern part of the Ross Ice Shelf, and in the coastal region of the southeastern corner of the Bel- lingshausen Sea match that of Vaughan's analysis (see Fig. 1 for locations). Comparing these two maps, several differences also exist: First, areas enclosed by the 20 and $50 \mathrm{~mm} \mathrm{yr}^{-1}$ contour lines in the simulated field are larger than those shown by Vaughan et al. (1999) and the simulated $P-E$ values in the enclosed areas are

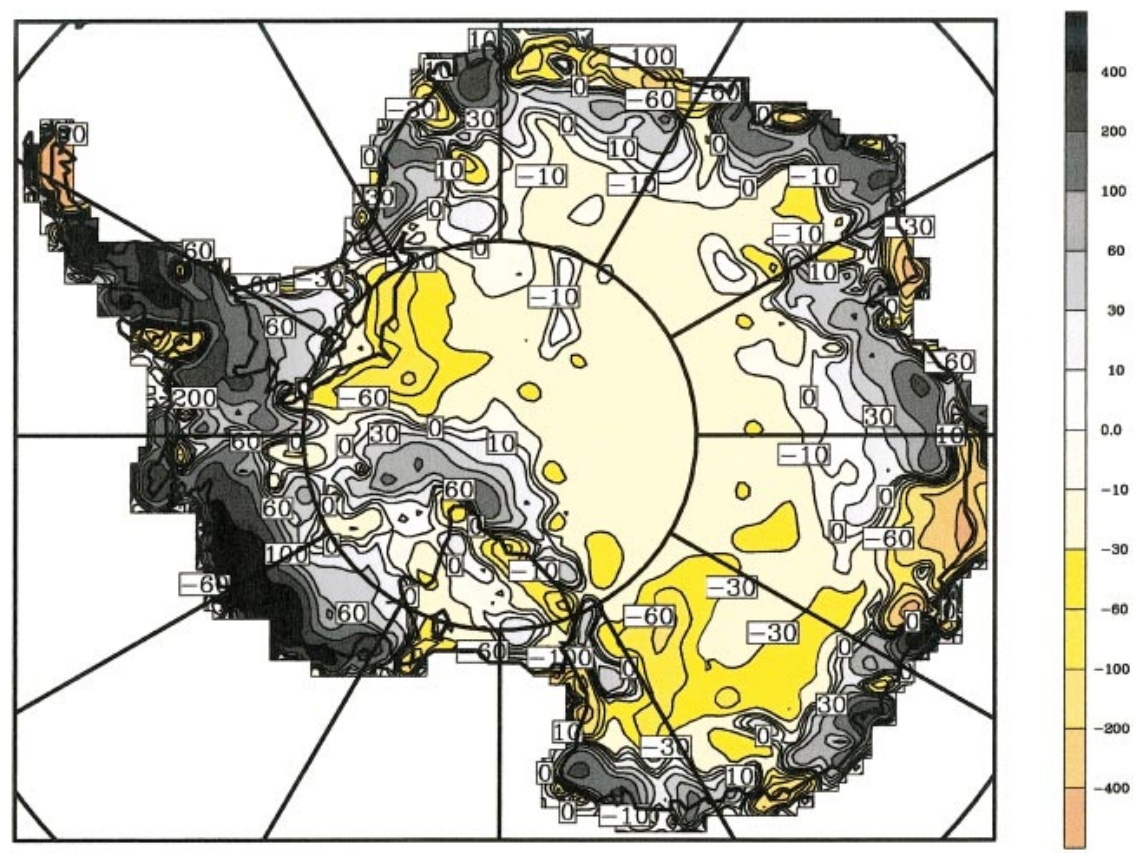

FIG. 4. Annual accumulation (precipitation minus sublimation) estimated from Polar MM5 simulations minus Vaughan et al. (1999) compiled accumulation ( $\mathrm{mm} \mathrm{yr}^{-1}$ water equivalent). 


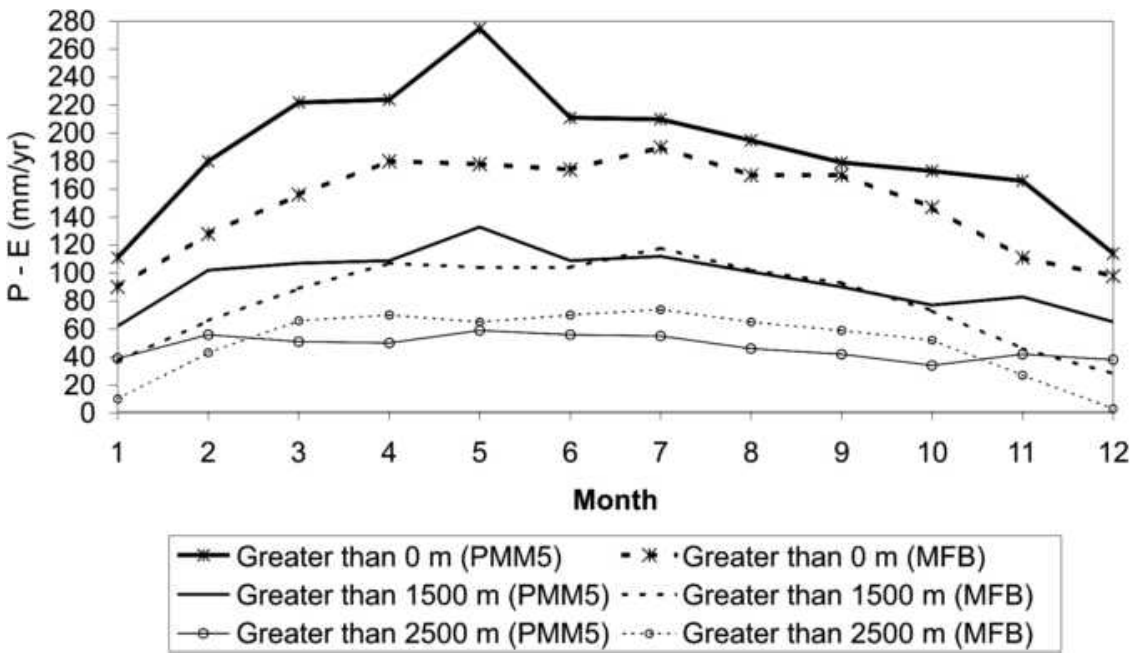

FIG. 5. Annual cycle of accumulation derived from Polar MM5 (PMM5) simulations and moisture flux budget calculations using ECMWF analyses for Antarctic continent above various elevation intervals $\left(\mathrm{mm} \mathrm{yr}^{-1}\right.$ water equivalent).

smaller than the climatologically depicted annual accumulation from Vaughan et al. (1999). Second, the area with small simulated $P-E$ values around the southern part of the Lambert Glacier is much smaller than that from Vaughan et al. (1999). As discussed below, the divergence of drift snow transport due to the strong katabatic winds in this area partially contributes to the difference between the simulated $P-E$ and observed accumulation. Third, although the accumulation peaks along the Antarctic Peninsula in the Polar MM5 output and Vaughan's analysis with a maximum around 2000 $\mathrm{mm}$, the accumulation distributions differ in this area. It is believed that the coarse spatial resolution of the Polar MM5 accounts for this difference. These features also can be observed in Fig. 4 where the Vaughan et al. (1999) accumulation compilation (Fig. 2) is subtracted from the averaged $P-E$ field derived from the Polar MM5 simulations (Fig. 3). Not surprisingly, the largest errors are associated with the coastal regions, and accumulation is underestimated in the central interior while it is generally overestimated in the coastal areas by Polar MM5. This is very similar to Genthon and Krinner's (2001) findings for their seven different GCMs. Cassano et al. (2001) found that Polar MM5 also overestimates the precipitation amounts along the steep slopes of the Greenland Ice Sheet. It is hypothesized that the deficiencies in the interior precipitation simulations reflect the limited ability of Polar MM5 in representing clear sky precipitation. Studies show that clear sky precipitation is continuously formed in the interior of Antarctica without any organized synopticscale process, and comprises a large fraction of the total precipitation (Bromwich 1988). The time series of the precipitation events in MM5 over all interior sites appears to be episodic (not shown). This suggests that the simulated deficit accumulation reflects the limited abil- ity of Polar MM5 in representing clear sky precipitation. The annual cycle of accumulation derived from Polar MM5 simulations also supports the above hypothesis. Figure 5 shows the annual cycle of accumulation derived from Polar MM5 simulations and moisture flux budget calculations using ECMWF analysis for the Antarctic continent (Cullather et al. 1998, for 1985-94) above various elevation intervals. A broad peak of accumulation is found during March-October for the three elevation bands examined in moisture flux budget calculations. This peak in the interior of Antarctica is believed to result from the increased clear sky precipitation during the polar night when moisture saturation is enhanced by the strong radiative cooling (Bromwich 1988), and it does not appear in the Polar MM5 simulations for accumulation above $2500 \mathrm{~m}$.

To isolate the effect of sublimation on the comparison of precipitation and accumulation from different datasets, Fig. 6 shows the annual fraction sublimation/precipitation (SU/PR) from the Polar MM5 output. The mean annual sublimation field from Polar MM5 simulations is very close to that estimated by van den Broeke (1997). Similar to van den Broeke (1997), four areas clearly stand out where sublimation on an annual basis removes more than $70 \%$ of the precipitation: east Dronning Maud Land, the Lambert Glacier basin, Victoria Land, and the southern part of the Ross Ice Shelf. Averaged over the continent, the model predicts that $13.5 \%$ of the annual precipitation over Antarctica is removed by sublimation. Over most areas in the interior of the Antarctic ice sheets, SU/PR is less than 20\%. Similar to Genthon and Krinner's (2001) findings, deposition (or inverse sublimation) also contributes to the surface accumulation, and the contribution is not negligible. In addition, areas with a large contribution of sublimation removal are not associated with systematic underesti- 


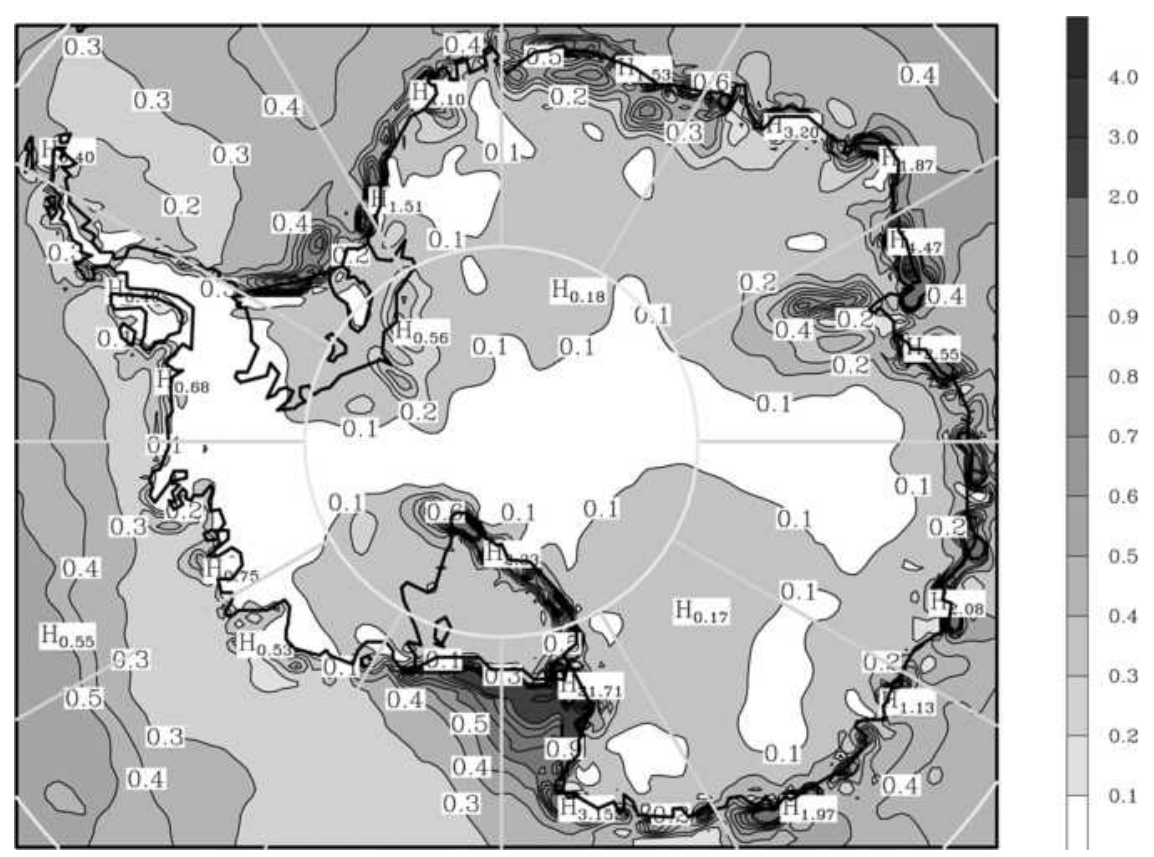

FIG. 6. Polar MM5 modeled fraction of the annual precipitation (PR) that is removed from the surface by sublimation (SU).

mation of surface accumulation, and areas with small contribution of sublimation removal are not associated with systematic overestimation of surface accumulation. Therefore, the deficiencies found in simulated accumulation are more likely attributed to deficiencies in precipitation rather than sublimation.

Katabatic winds are prominent climatological features of the Antarctic boundary layer. The associated drift snow effects are of importance for the redistribution of the snowfall, and for modification of the local net accumulation by direct removal of snow across the coastline and by enhancing evaporative loss from the surface. The Byrd snow drift project (Budd et al. 1966) executed during 1962-63 found that the observed drift snow transport in the layer from $1 \mathrm{~mm}$ to $300 \mathrm{~m}$ above the snow surface, $Q_{10^{-3}}^{300}$ (units: $\mathrm{g} \mathrm{m}^{-1} \mathrm{~s}^{-1}$ ), can be represented by the relation

$$
\log \left|\mathbf{Q}_{10^{-3}}^{300}\right|=1.1812+0.0887\left|\mathbf{V}_{10}\right|,
$$

where $\mathbf{V}_{10}$ is the wind velocity at $10 \mathrm{~m}$ above the snow surface. The snow transport follows the wind direction. Thus, the drift snow effects can be expressed as the divergence or convergence of the snow transport vectors:

$$
D=\boldsymbol{\nabla} \cdot\left(\frac{\left|\mathbf{Q}_{10^{-3}}^{300}\right|}{\left|\mathbf{V}_{10}\right|} \mathbf{V}_{10}\right) \text {. }
$$

Using the above equation with wind field output from Polar MM5 simulations at 3-h intervals, drift snow effects can be estimated. Figure 7 shows annual mean divergence of drift snow transport estimated from the surface wind fields simulated by Polar MM5 for July 1996-June 1999. The dashed lines are elevation con- tours. The results show that there are complex divergence and convergence patterns of drift snow transport over Antarctica, especially along the coast. From this figure several features can be observed. First, areas with large drift snow transport convergence and divergence are located around escarpment areas where there is large katabatic wind acceleration. Second, drift snow transport generally diverges over most areas of East and West Antarctica with relatively small amounts. Third, areas with large snow transport divergence are generally accompanied by areas with large snow transport convergence nearby, and this indicates that the drift snow transport is of local importance for redistribution of the snowfall. Finally, the southern part of the Lambert Glacier is one of the areas with the largest divergence of drift snow transport. The divergence of drift snow transport under strong katabatic winds partially contributes to the difference between the simulated $P-E$ and observed accumulation over this area. It is noted that this method neglects the enhancement of sublimation of snow when it is airborne (Gallee 1998; Bintanja and Reijmer 2001) and does not consider variations in the quantity of snow available for transport.

In Fig. 8, the Vaughan et al. (1999) accumulation compilation (Fig. 2) is subtracted from the averaged $P-E-D$ field derived from the Polar MM5 simulations (Fig. 7). When compared to Fig. 4 [Polar MM5 $P-E$ minus Vaughan et al. (1999)], this plot demonstrates that accounting for the drift transport with this method has little impact on the accumulation estimates. Not surprisingly, the largest errors in accumulation are associated with the coastal regions. As before, it is also 


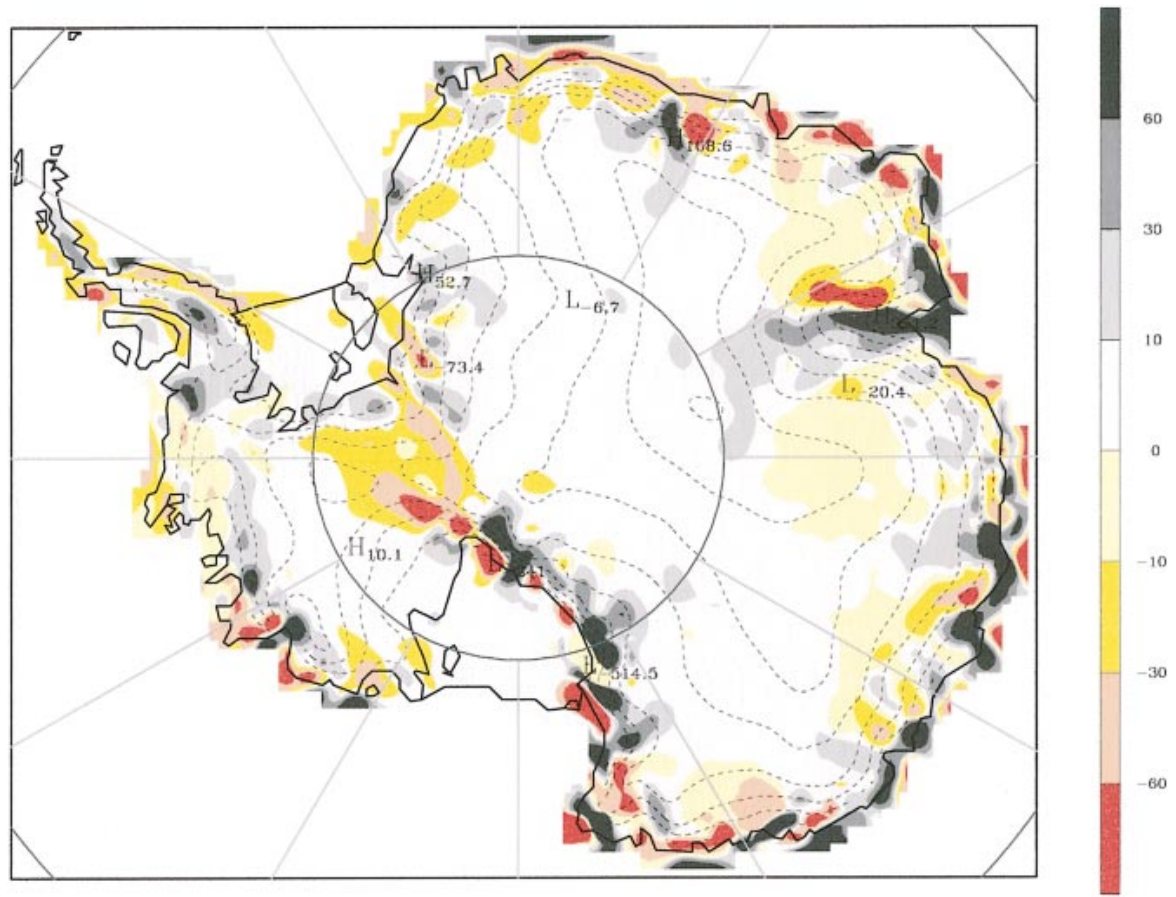

FIG. 7. Mean annual divergence of drift snow transport over Antarctica ( $\mathrm{mm} \mathrm{yr}^{-1}$ water equivalent). The drift snow transport is estimated by the Budd et al. (1966) equation from wind fields at $10 \mathrm{~m}$ above the surface. The wind fields are derived from the Polar MM5 simulations.

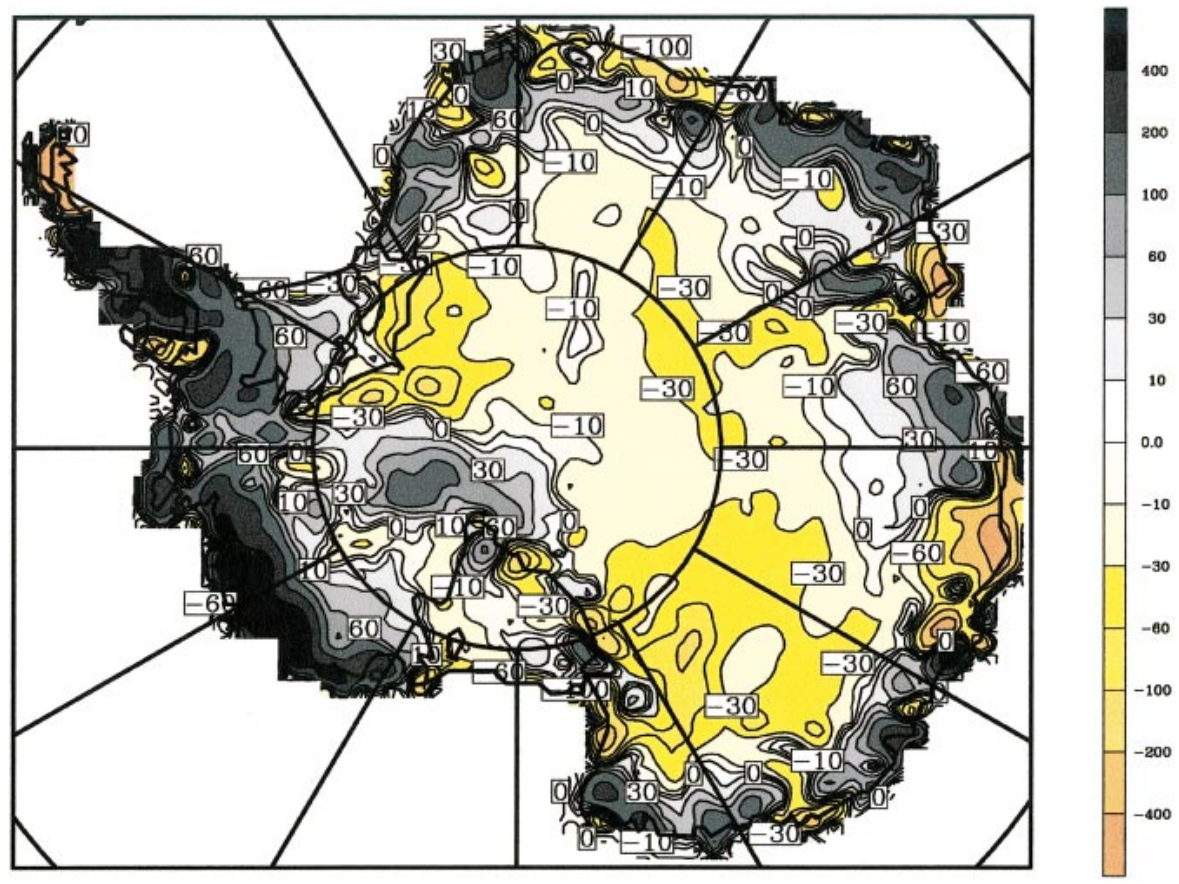

FIG. 8. Annual accumulation (precipitation minus sublimation and divergence of drift snow transport) estimated from Polar MM5 simulations minus Vaughan et al. (1999) compiled accumulation ( $\mathrm{mm} \mathrm{yr}^{-1}$ water equivalent). 


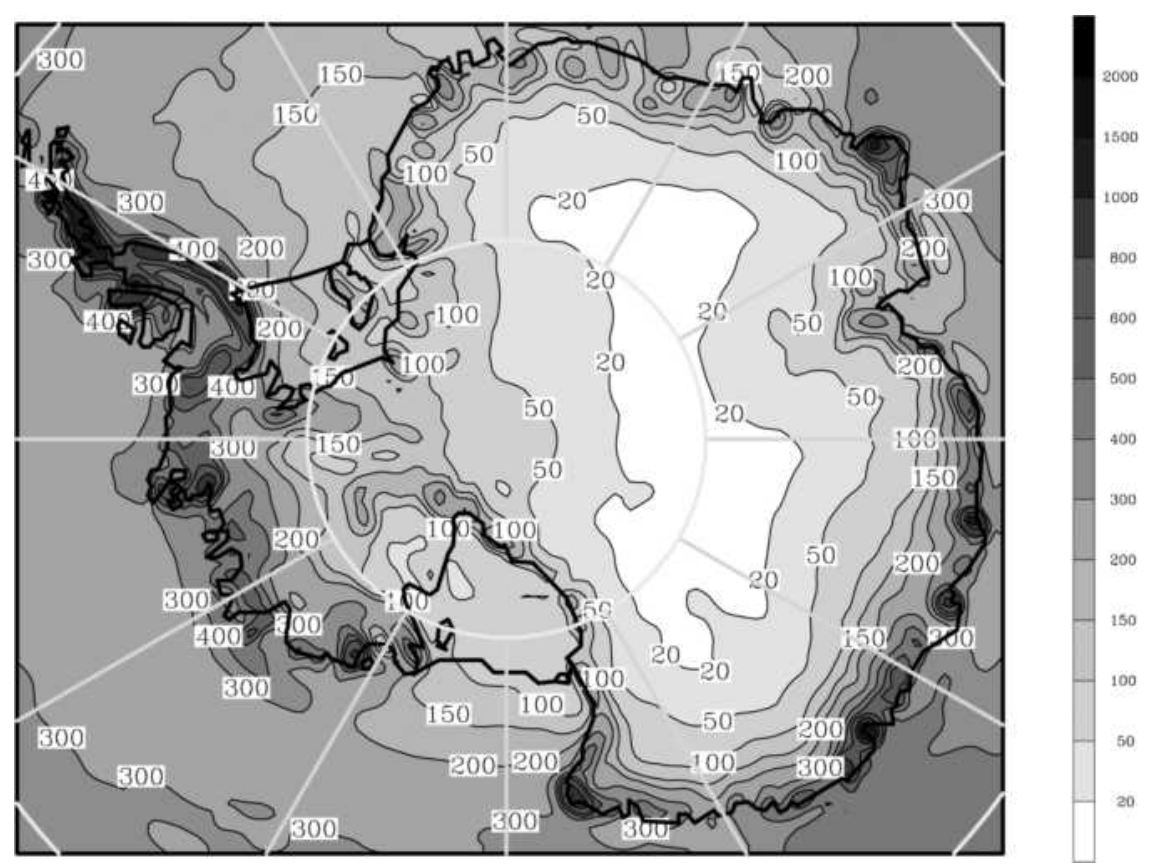

FIG. 9. Mean annual precipitation for 1985-99 derived from the dynamic retrieval method (mm $\mathrm{yr}^{-1}$ water equivalent).

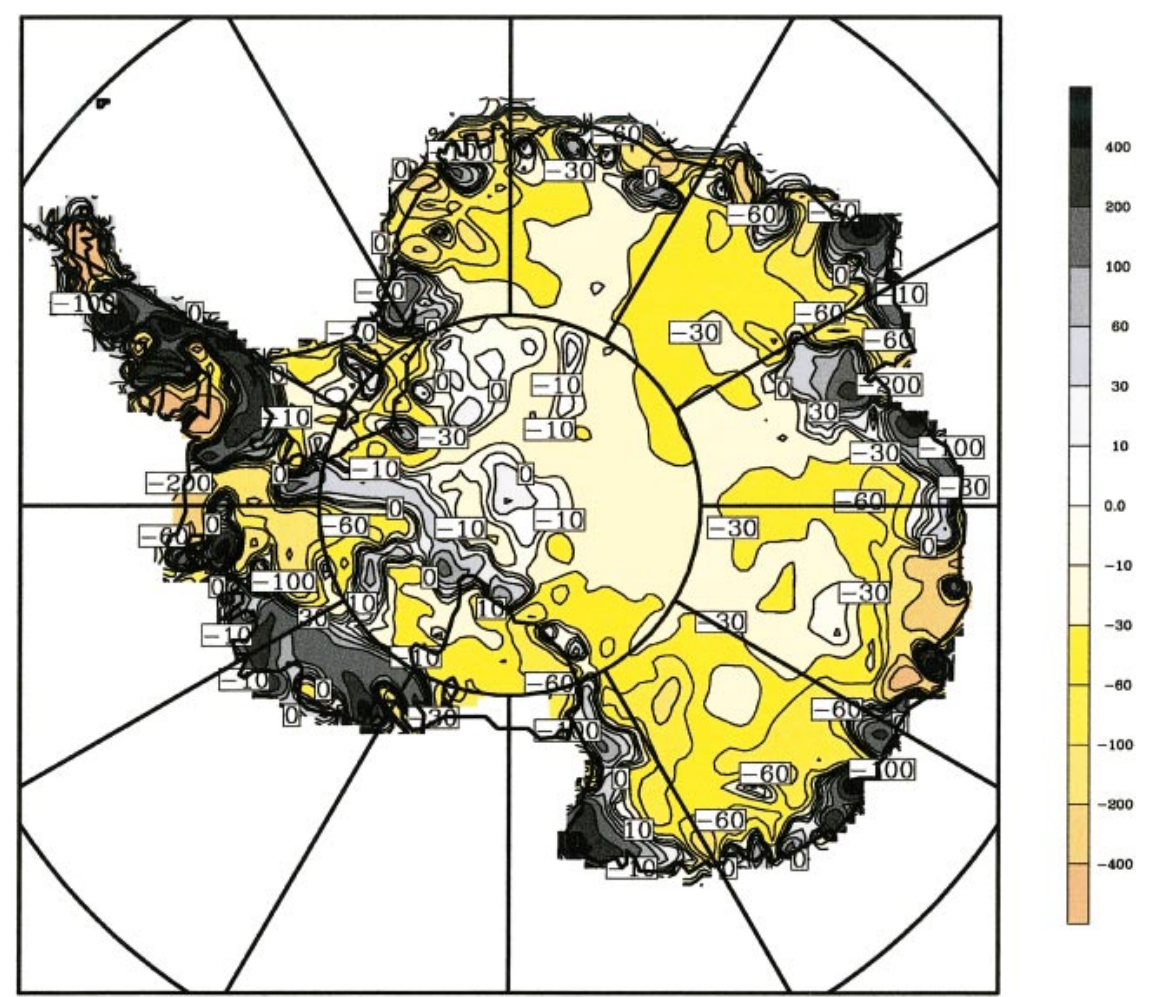

FIG. 10. Annual precipitation for 1985-99 derived from the dynamic retrieval method minus Vaughan et al. (1999) compiled accumulation ( $\mathrm{mm} \mathrm{yr}^{-1}$ water equivalent). 


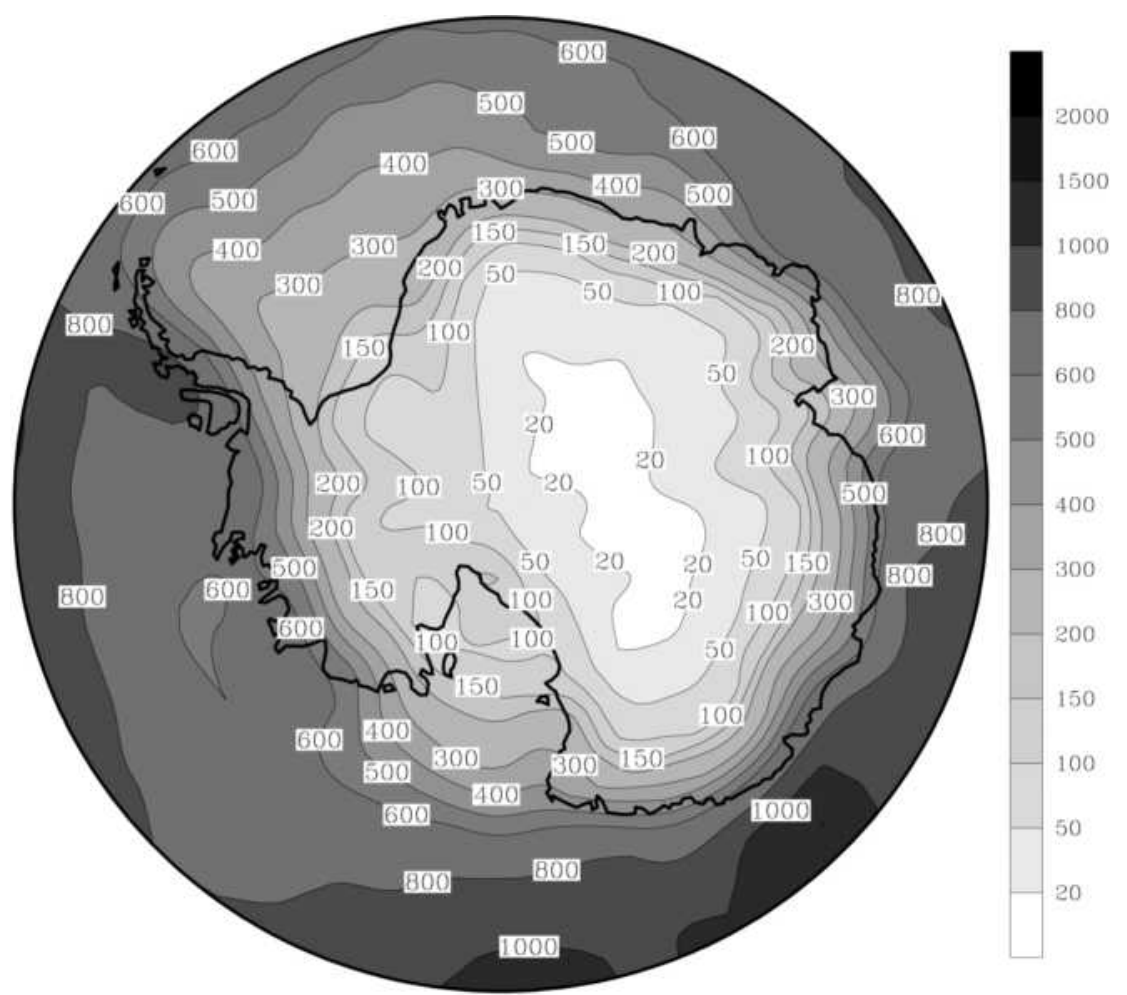

FIG. 11. Mean annual precipitation produced by NCEP2 for the years $1979-99\left(\mathrm{~mm} \mathrm{yr}^{-1}\right.$ water equivalent).

observed that accumulation is underestimated in the central interior while it is generally overestimated in the coastal areas by Polar MM5.

Figure 9 shows the annual mean precipitation determined from the DRM using ECMWF analysis (DRM_ECT, 1985-99). All major features in the spatial distribution of Antarctic precipitation from the Polar MM5 simulations mentioned above are well captured by the DRM. These features include the maximum values over the Antarctic Peninsula and a large amount of precipitation on the southern coast of the Bellingshausen Sea. Over Marie Byrd Land, the greatest precipitation occurs in the immediate coastal region and rapidly decreases inland. The primary difference is the deficient precipitation over the ocean derived from the DRM compared to that simulated by Polar MM5. Studies show that the dependence of effective precipitation on the relative humidity is spatially complex (Sinclair 1994). The fixed value of $r_{c}$ is optimized for use over the Antarctic continent and is set too high for use over the ocean (contributing to the underestimation of precipitation here). Also, only large-scale condensation is considered by the DRM in computing precipitation; the omission of mesoscale convection and associated precipitation over the ocean contributes to the difference. The Vaughan et al. (1999) accumulation compilation (Fig. 2 ) is subtracted from the average $P$ field derived from the DRM (Fig. 9) in Fig. 10. As with Polar MM5, a similar problem in reproducing clear sky precipitation exists in the DRM, and a new scheme is currently being developed to represent clear sky precipitation events.

Figures 11 and 12 show the annual mean forecast precipitation from NCEP2 (1979-99) and ECT (199199), respectively. All modeled values from Polar MM5, DRM, ECT, and NCEP2 agree with each other in representing the general spatial features of the modern Antarctic precipitation. Because Polar MM5 and DRM use resolutions of 60 and $40 \mathrm{~km}$, respectively, they resolve more mesoscale precipitation features. In particular, NCEP2 shows a smoothed version of the annual-mean precipitation distribution around the coast of the Bellingshausen Sea and Marie Byrd Land. While all datasets show a reasonable spatial distribution of Antarctic precipitation, it is also noted that they tend to underestimate the precipitation in the interior of Antarctica. Table 1 (following Reijmer et al. 2002) presents the annual mean precipitation from ice core measurements and model outputs at six locations with high elevation (Fig. 1). It shows that most modeled precipitation values are much less than their measured counterparts (around $30 \%-50 \%$ if sublimation is taken into account). This suggests that simulation of the moist physical processes involved in Antarctic precipitation needs further improvement.

Table 2 compares the average annual precipitation and accumulation for all of Antarctica (the Antarctic con- 


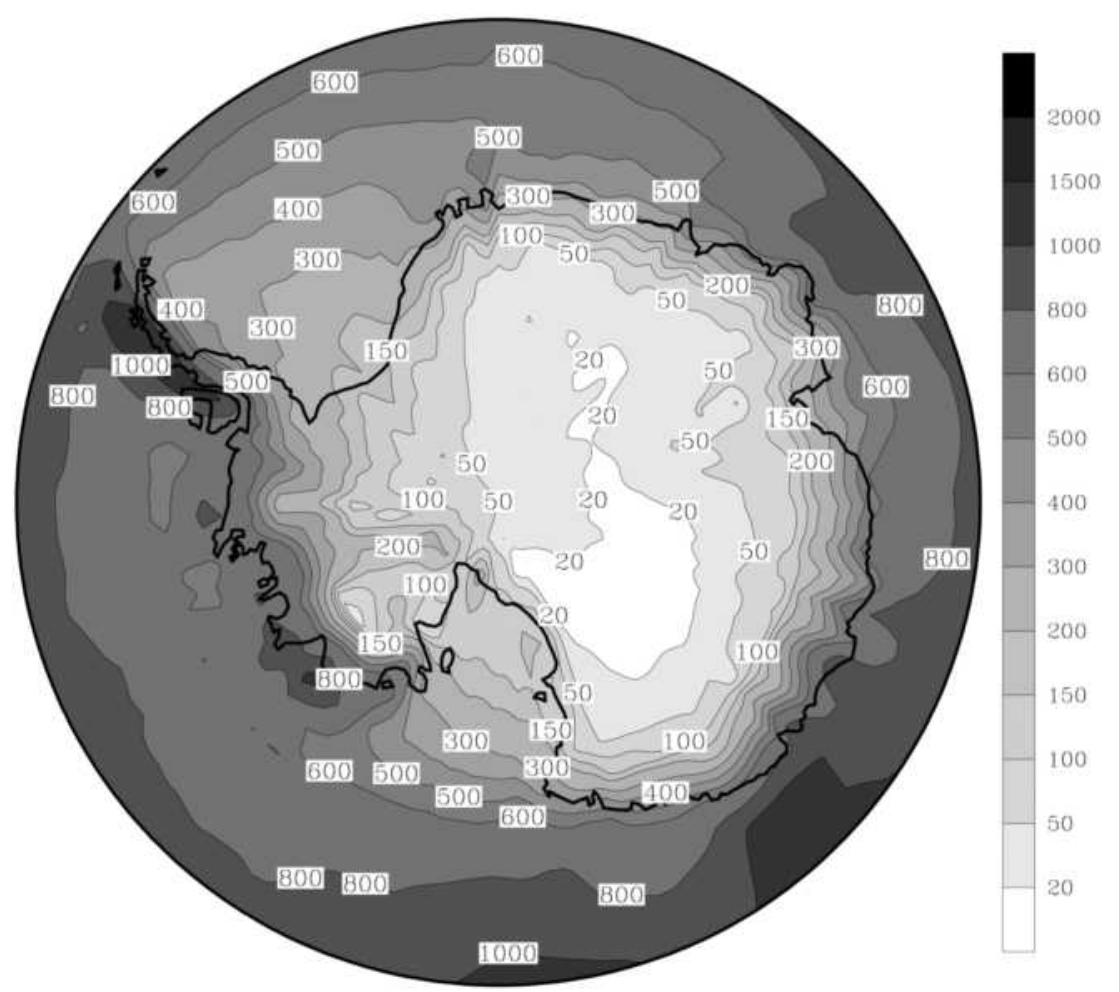

FIG. 12. The mean annual precipitation produced by ECT for the years $1991-99\left(\mathrm{~mm} \mathrm{yr}^{-1}\right.$ water equivalent).

tinent, Antarctic Peninsula, and floating shelves) from modeled values with the results reported by other investigators. The mean annual precipitation for the whole Antarctica, as computed from the DRM with ERA-15 and ECT data, is 179 and $195 \mathrm{~mm} \mathrm{yr}^{-1}$, respectively. They are close to the forecast precipitation from ERA15, ECT, and NCEP2. Considering annual sublimation of $29 \mathrm{~mm} \mathrm{yr}^{-1}$ from Polar MM5 simulations, the mean annual mean net accumulation $(P-E)$ is close to previously reported values (Cullather et al. 1998; Vaughan et al. 1999). However, mean annual precipitation and accumulation derived from the DRM and forecast precipitation from ERA-15, ECT, and NCEP2 is much less than that simulated by the high-resolution mesoscale model (Polar MM5) and a general circulation model (Ohmura et al. 1996). The mean annual precipitation for the whole Antarctica estimated by the Polar MM5 is $215 \mathrm{~mm} \mathrm{yr}^{-1}$. The sublimation on an annual basis removes about $13.5 \%$ of the precipitation, and the drift snow transport removes about $2.3 \%$ of the precipitation.

\section{The temporal variability of Antarctic precipitation}

Here, the temporal variability of Antarctic precipitation and the recent precipitation trends over the Antarctic ice sheets are presented. The temporal changes present in the precipitation time series produced by the
DRM are contrasted with those derived from the analysis and reanalysis forecast products, and they are also compared with available ice core accumulation measurements. The ENSO signal in modeled Antarctic precipitation is evaluated in the second part of this work (GBH).

\section{a. Interannual variations of precipitation over Antarctica and its subregions}

Figure 13a compares the monthly mean modeled precipitation over all of Antarctica from various methods. There is good agreement on seasonal time scales in modeled Antarctic precipitation among these datasets when averaged over all of Antarctica for both raw and detrended estimates (Table 3: $r \approx 0.70 ; r^{2} \approx 0.50$ ). The seasonality of modeled precipitation is generally identifiable with a maximum in winter and a minimum in summer. The annual time series for the modeled precipitation over all of Antarctica from various methods are shown in Fig. 13b. The estimates do not agree as well as for the seasonal case, especially for the detrended estimates, $\left(r \lessgtr 0.20 ; r^{2} \lesssim 0.04\right)$. In the DRM precipitation, the largest amount $\left(215 \mathrm{~mm} \mathrm{yr}^{-1}\right)$ occurs in 1998 , and the smallest amount $\left(176 \mathrm{~mm} \mathrm{yr}^{-1}\right)$ occurs in 1987 and 1979. The 21-yr mean precipitation over all of Antarctica is $183 \mathrm{~mm} \mathrm{yr}^{-1}$, and the standard deviation is $15.3 \mathrm{~mm} \mathrm{yr}^{-1}$. The correlation between the ERA-15- 
TABLE 1. The annual mean values of the observed accumulation [after Reijmer et al. (2002) except for the South Pole] and various modeled precipitation for six sites in the interior of Antarctica. Values preceded by \pm indicate the standard deviation $(P=$ precipitation, $E=$ sublimation, PMM5 = Polar MM5). References for accumulation values at each site, left to right respectively, are as follows: Herron (1982); Petit et al. (1982); Aoki and Coauthors (1998); Oerter et al. (2000); Legrand and Delmas (1987); E.-F. Mosley-Thompson (2002, personal communication).

\begin{tabular}{|c|c|c|c|c|c|c|c|}
\hline & Byrd & Dome $\mathrm{C}$ & Dome F & DML05 & Vostok & South Pole & Data source \\
\hline Lat & $80.00^{\circ} \mathrm{S}$ & $74.50^{\circ} \mathrm{S}$ & $77.32^{\circ} \mathrm{S}$ & $75.00^{\circ} \mathrm{S}$ & $78.50^{\circ} \mathrm{S}$ & $90.0^{\circ} \mathrm{S}$ & \\
\hline Lon & $119.4^{\circ} \mathrm{W}$ & $123.0^{\circ} \mathrm{E}$ & $39.70^{\circ} \mathrm{E}$ & $0.0^{\circ}$ & $106.9^{\circ} \mathrm{E}$ & & \\
\hline Elevation (m) & 1530 & 3280 & 3810 & 2892 & 3488 & 2835 & \\
\hline Accumulation $\left(\mathrm{mm} \mathrm{yr}^{-1}\right)$ & 160 & $36 \pm 5$ & 30 & $62 \pm 21$ & 22.5 & $79 \pm 7$ & $\begin{array}{l}\text { Ice core (Byrd-Vostok), } \\
\text { snow stakes (South Pole) }\end{array}$ \\
\hline$P\left(\mathrm{~mm} \mathrm{yr}^{-1}\right)$ & $146 \pm 41$ & $40 \pm 14$ & $22 \pm 9$ & $55 \pm 19$ & $14 \pm 6$ & $40 \pm 10$ & NR2_P 1979-99 \\
\hline $\mathrm{P}\left(\mathrm{mm} \mathrm{yr}^{-1}\right)$ & $168 \pm 61$ & $21 \pm 6$ & $7 \pm 3$ & $27 \pm 7$ & $5 \pm 1$ & $51 \pm 6$ & ERA_P 1979-93 \\
\hline$P\left({\left.\mathrm{~mm} \mathrm{yr}^{-1}\right)}^{-1}\right.$ & $126 \pm 28$ & $28 \pm 6$ & $20 \pm 4$ & $42 \pm 13$ & $15 \pm 5$ & $50 \pm 10$ & ECT_P 1991-99 \\
\hline$P\left({\left.\mathrm{~mm} \mathrm{yr}^{-1}\right)}^{\prime}\right.$ & $154 \pm 26$ & $25 \pm 9$ & $15 \pm 3$ & $43 \pm 8$ & $20 \pm 3$ & $72 \pm 12$ & DRM with ERA 1979-93 \\
\hline$P\left(\mathrm{~mm} \mathrm{yr}^{-1}\right)$ & $165 \pm 21$ & $26 \pm 12$ & $14 \pm 2$ & $44 \pm 14$ & $23 \pm 8$ & $71 \pm 14$ & DRM with ECT 1985-99 \\
\hline$P\left(\mathrm{~mm} \mathrm{yr}^{-1}\right)$ & $144 \pm 49$ & $25 \pm 6$ & $26 \pm 5$ & $105 \pm 4$ & $18 \pm 9$ & $66 \pm 7$ & PMM5 1996.7/1999.6 \\
\hline$P-E\left(\mathrm{~mm} \mathrm{yr}^{-1}\right)$ & $126 \pm 46$ & $22 \pm 5$ & $22 \pm 5$ & $96 \pm 4$ & $15 \pm 8$ & $64 \pm 6$ & PMM5 1996.7/1999.6 \\
\hline$E / P(\%)$ & 12.8 & 10.6 & 12.2 & 8.4 & 11.7 & 4.0 & PMM5 1996.7/1999.6 \\
\hline
\end{tabular}

ECT forecast precipitation and the DRM precipitation is poor from 1991 to 1995; these two time series converge by 1996. In September 1991 several major changes were made to the ECMWF forecast model, including increased horizontal resolution and dynamics modifications such as a new version of cloud treatment (ECMWF 1999). Inspection of the monthly mean ECT precipitation fields from this time through March 1995 reveal a significant degree of spectral noise; this problem disappeared with the implementation of a new version of the ECMWF forecast model in April 1995, which led to a greatly improved representation of cloud cover and forecast precipitation (ECMWF 1999). Better agreement between the DRM precipitation and ECT forecast precipitation after 1995 might indicate that the interannual variability of DRM Antarctic precipitation is more reliable during 1991-95 since the method does not rely on the ECT precipitation fields but rather on other ECT fields that were largely unaffected by the changes made in September 1991. Because no cloud microphysics is included in the DRM, less artificial interannual variability will be introduced into DRM precipitation compared to the ECT forecast precipitation due to changing cloud and microphysics schemes.

The annual time series for the modeled precipitation from various methods over Antarctica for elevations higher than $2000 \mathrm{~m}$ are shown in Fig. 14. It shows that the DRM precipitation over high elevations is much

TABLE 2. Comparison of recent estimates of Antarctic accumulation and precipitation. Values preceded by \pm indicate the standard deviation.

\begin{tabular}{|c|c|c|c|}
\hline Study & Estimate & Method & $\begin{array}{c}\text { Value } \\
\left(\mathrm{mm} \mathrm{yr}^{-1}\right)\end{array}$ \\
\hline Giovinetto and Bentley (1985) & Accumulation & Glaciological data synthesis & $143 \pm 14$ \\
\hline Vaughan et al. (1999) & Accumulation & Glaciological data synthesis & 166 \\
\hline Ohmura et al. (1996) & $P-E$ & $\begin{array}{l}\text { Modeled precipitation minus evaporation from } \\
\text { ECHAM coupled model }\end{array}$ & 197 \\
\hline Cullather et al. (1998) & $P-E$ & $\begin{array}{l}\text { Atmospheric moisture budget from ECMWF, } \\
\text { 1985-94 }\end{array}$ & $151 \pm 13$ \\
\hline This study & $P-E$ & $\begin{array}{l}\text { Modeled precipitation minus sublimation from Polar } \\
\text { MM5, Jul 1996-Jun } 1999\end{array}$ & $186 \pm 16$ \\
\hline This study & $P-E-D$ & $\begin{array}{l}\text { Modeled precipitation minus sublimation and drift } \\
\text { snow divergence from Polar MM5 }\end{array}$ & $181 \pm 16$ \\
\hline This study & $P$ & $\begin{array}{l}\text { Modeled precipitation from Polar MM5, Jul 1996- } \\
\text { Jun } 1999\end{array}$ & $215 \pm 15$ \\
\hline This study & $P$ & NCEP-DOE AMIP-2 reanalysis, 1979-2000 & $180 \pm 12$ \\
\hline This study & $P$ & 15-yr ECMWF Re-analysis, 1979-93 & $173 \pm 7$ \\
\hline This study & $P$ & ECMWF TOGA analysis, 1991-99 & $188 \pm 20$ \\
\hline This study & $P$ & $\begin{array}{l}\text { Dynamic retrieval method with ECMWF reanalysis } \\
\text { data, 1979-93 }\end{array}$ & $179 \pm 5$ \\
\hline This study & $P$ & $\begin{array}{l}\text { Dynamic retrieval method with ECMWF analysis } \\
\text { data, 1985-99 }\end{array}$ & $195 \pm 16$ \\
\hline This study & $E$ & $\begin{array}{l}\text { Modeled sublimation from Polar MM5, Jul 1996-Jun } \\
1999\end{array}$ & $29 \pm 1$ \\
\hline This study & $D$ & $\begin{array}{l}\text { Divergence of drift snow transport from Polar MM5, } \\
\text { Jul 1996-Jun } 1999\end{array}$ & 5 \\
\hline
\end{tabular}



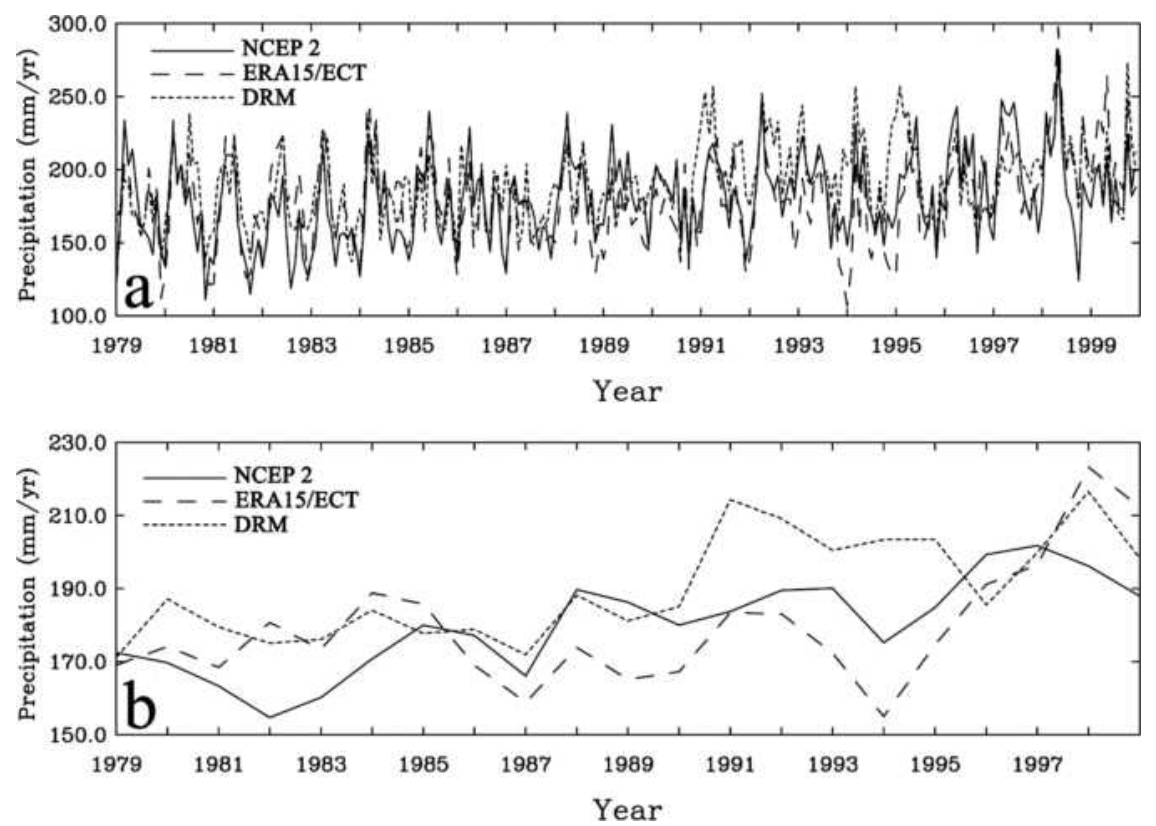

FIG. 13. (a) Monthly and (b) annual time series for the modeled precipitation over all of Antarctica.

TABLE 3. Monthly and interannual correlation $(r)$ and variance $\left(r^{2}\right)$ statistics for the raw and detrended time series in Figs. 13-18. Correlations that meet the $95 \%$ confidence interval are shown in bold type.

\begin{tabular}{|c|c|c|c|c|c|c|c|c|}
\hline & \multicolumn{4}{|c|}{ Raw } & \multicolumn{4}{|c|}{ Detrended } \\
\hline & \multicolumn{2}{|c|}{ Monthly } & \multicolumn{2}{|c|}{ Interannual } & \multicolumn{2}{|c|}{ Monthly } & \multicolumn{2}{|c|}{ Interannual } \\
\hline & $r$ & $r^{2}$ & $r$ & $r^{2}$ & $r$ & $r^{2}$ & $r$ & $r^{2}$ \\
\hline \multicolumn{9}{|c|}{ Fig. 13: Precipitation over all of Antarctica } \\
\hline ERA-15-ECT vs NCEP2 & 0.73 & 0.53 & 0.5 & 0.25 & 0.71 & 0.50 & 0.18 & 0.03 \\
\hline DRM vs ERA-15-ECT & 0.71 & 0.50 & 0.41 & 0.17 & 0.69 & 0.48 & 0.08 & 0.01 \\
\hline DRM vs NCEP2 & 0.67 & 0.45 & 0.58 & 0.34 & 0.61 & 0.37 & 0.04 & 0.00 \\
\hline \multicolumn{9}{|c|}{ Fig. 14: Precipitation above $2000 \mathrm{~m}$} \\
\hline ERA-15-ECT vs NCEP2 & 0.52 & 0.27 & 0.63 & 0.40 & 0.46 & 0.21 & 0.2 & 0.04 \\
\hline DRM vs ERA-15-ECT & 0.48 & 0.23 & 0.51 & 0.26 & 0.48 & 0.23 & 0.39 & 0.15 \\
\hline DRM vs NCEP2 & 0.46 & 0.21 & 0.37 & 0.14 & 0.46 & 0.21 & 0.15 & 0.02 \\
\hline \multicolumn{9}{|c|}{ Fig. 15: Precipitation over the West Antarctic sector } \\
\hline ERA-15-ECT vs NCEP2 & 0.85 & 0.72 & 0.82 & 0.67 & 0.85 & 0.72 & $\mathbf{0 . 8 3}$ & 0.69 \\
\hline DRM vs ERA-15-ECT & 0.9 & 0.81 & 0.83 & 0.69 & 0.91 & 0.83 & 0.86 & 0.74 \\
\hline DRM vs NCEP2 & $\mathbf{0 . 8 1}$ & 0.66 & 0.87 & 0.76 & 0.82 & 0.67 & $\mathbf{0 . 8 8}$ & 0.77 \\
\hline \multicolumn{9}{|c|}{ Fig. 16: Precipitation over the South Atlantic sector } \\
\hline ERA-15-ECT vs NCEP2 & 0.76 & 0.58 & 0.68 & 0.46 & 0.76 & 0.58 & 0.66 & 0.44 \\
\hline DRM vs ERA-15-ECT & 0.71 & 0.50 & 0.61 & 0.37 & 0.71 & 0.50 & 0.57 & 0.32 \\
\hline DRM vs NCEP2 & 0.75 & 0.56 & 0.76 & 0.58 & 0.75 & 0.56 & 0.75 & 0.56 \\
\hline \multicolumn{9}{|c|}{ Fig. 17: Modeled precipitation vs FB9815 ice core } \\
\hline DRM vs measured & $\mathrm{n} / \mathrm{a}$ & $\mathrm{n} / \mathrm{a}$ & 0.42 & 0.18 & $\mathrm{n} / \mathrm{a}$ & $\mathrm{n} / \mathrm{a}$ & 0.26 & 0.07 \\
\hline ERA-15-ECT vs measured & $\mathrm{n} / \mathrm{a}$ & $\mathrm{n} / \mathrm{a}$ & 0.50 & 0.25 & $\mathrm{n} / \mathrm{a}$ & $\mathrm{n} / \mathrm{a}$ & 0.35 & 0.12 \\
\hline NCEP 2 vs measured & $\mathrm{n} / \mathrm{a}$ & $\mathrm{n} / \mathrm{a}$ & 0.18 & 0.03 & $\mathrm{n} / \mathrm{a}$ & $\mathrm{n} / \mathrm{a}$ & 0.10 & 0.01 \\
\hline \multicolumn{9}{|c|}{ Fig. 18: Modeled precipitation vs South Pole snow stakes } \\
\hline DRM vs measured & $\mathrm{n} / \mathrm{a}$ & $\mathrm{n} / \mathrm{a}$ & 0.49 & 0.24 & $\mathrm{n} / \mathrm{a}$ & $\mathrm{n} / \mathrm{a}$ & 0.34 & 0.12 \\
\hline ERA-15-ECT vs measured & $\mathrm{n} / \mathrm{a}$ & $\mathrm{n} / \mathrm{a}$ & 0.61 & 0.37 & $\mathrm{n} / \mathrm{a}$ & $\mathrm{n} / \mathrm{a}$ & -0.21 & 0.04 \\
\hline NCEP 2 vs measured & $\mathrm{n} / \mathrm{a}$ & $\mathrm{n} / \mathrm{a}$ & -0.07 & 0.00 & $\mathrm{n} / \mathrm{a}$ & $\mathrm{n} / \mathrm{a}$ & -0.07 & 0.01 \\
\hline
\end{tabular}


TABLE 4. Temporal trend and uncertainty (at 95\%) of the linear regression ( $\mathrm{mm} \mathrm{yr}^{-2}$ water equivalent) for the interannual data series in Fig. 13. Bold numbers represent trends that are significant at the $95 \%$ confidence level with respect to zero.

\begin{tabular}{lcr}
\hline \hline \multicolumn{1}{c}{ Dataset } & Trend & Uncertainty \\
\hline Fig. 13: Precipitation over all of Antarctica & & Years \\
DRM & $\mathbf{1 . 6 5}$ & 0.80 \\
ERA-15-ECT & $\mathbf{1 . 3 5}$ & 1.10 \\
NCEP2 & $\mathbf{1 . 6 7}$ & 0.59 \\
\hline
\end{tabular}

larger than that obtained from NCEP2, ECT, and ERA15 simulated precipitation. As discussed in the previous section, simulated precipitation is significantly underestimated in the interior of Antarctica by ECT, ERA15 , and NCEP2 in comparison with measured accumulation. Based on the results in Table 1, the DRM precipitation provides a better quantitative estimate of precipitation over the interior of Antarctica than the simulated precipitation estimates. The relative agreement between the estimates above $2000 \mathrm{~m}$ is similar to that for the estimates for the entire continent (Table 3), although the seasonal (monthly) correlations are lower, suggesting the differences in the precipitation algorithms are most marked over the continental interior.

Because precipitation in the South Atlantic sector around the Weddell Sea and the West Antarctic sector around the Ross Sea (Fig. 1) is found to be highly correlated and anticorrelated with the SOI for the last two decades (Guo 2002; GBH), special attention is paid to these two sectors. Figure 15 shows the annual time series for the modeled precipitation over the West Antarctic sector bounded by $75^{\circ}-90^{\circ} \mathrm{S}, 120^{\circ} \mathrm{W}-180^{\circ} \mathrm{W}$. All three datasets agree closely with each other in reproducing both the seasonal (not plotted) and interannual variations in mean precipitation averaged over the West Antarctic sector (Table 3); all of the estimates correlate significantly at $>0.80$ for monthly and interannual scales for both the raw and detrended time series. Annual time series for the modeled precipitation over the South Atlantic sector bounded by $65^{\circ}-75^{\circ} \mathrm{S}, 30^{\circ}-60^{\circ} \mathrm{W}$ are shown in Fig. 16. Although precipitation over the South Atlantic sector is substantially underestimated by the DRM due to omission of mesoscale convection and associated precipitation and assumed high value of $r_{c}$, good agreement is found in the seasonal (not plotted) and inter- annual variations in South Atlantic precipitation from the various methods. Monthly correlations are $>0.70$ and interannual correlations range from 0.57 to 0.76 for both raw and detrended estimates. As discussed in $\mathrm{GBH}$, the good agreements in the seasonal and interannual variations in these sectors indicate that the ENSO signals in the interannual precipitation variations are strong enough to survive reproduction by methods with different representation of physical processes. Outside West Antarctica, especially in the continental interior, the correspondence in interannual variations among these datasets is generally less than that found in these two sectors.

\section{b. Comparison of the interannual variations at measurement sites in Antarctica between the measured accumulation and modeled precipitation}

Recently measured time series of net water equivalent accumulation at sites FB9815 and the South Pole are compared to the retrieved precipitation from DRM and forecast precipitation from analysis and reanalysis datasets. These sites were selected because they provide a reasonable sampling of the environments in the interior of the Antarctic continent and few choices are available for data comparison. The locations of these sites are shown in Fig. 1. The precipitation amounts at the grid points from various methods are interpolated to the measurement locations.

Figure 17 shows the interannual variations of the modeled precipitation from the various methods and the measured accumulation for 1979-96 at FB9815 (Oerter et al. 2000). There is reasonable agreement in the interannual variations between the measured accumulation and both the DRM and ERA-15-ECT precipitation

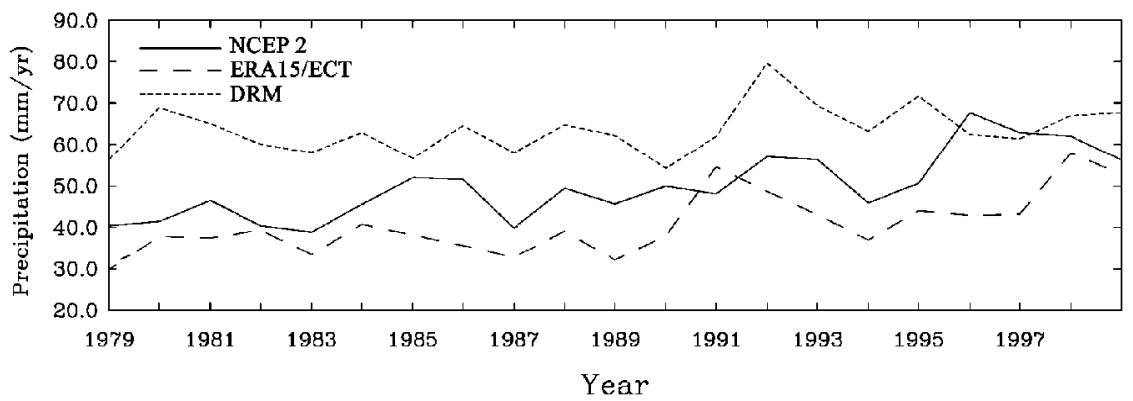

FIG. 14. Annual time series for the modeled precipitation over Antarctica for elevations higher than $2000 \mathrm{~m}$. 


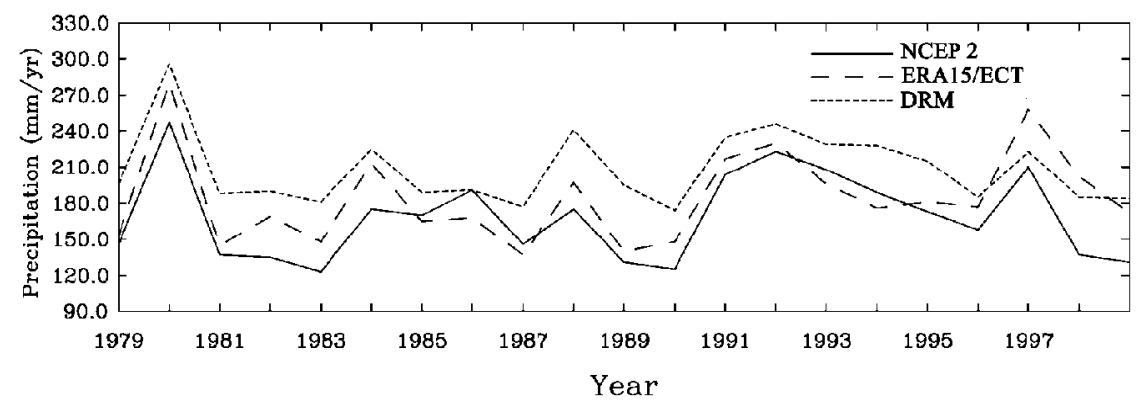

FIG. 15. Annual time series for the modeled precipitation over the West Antarctic sector bounded by $75^{\circ}-90^{\circ} \mathrm{S}, 120^{\circ} \mathrm{W}-180^{\circ}$.

for the raw estimates (Table 3 ). The correlation between the measured accumulation and DRM precipitation is 0.42 and 0.50 for the measured accumulation and ERA15-ECT; both are significant. The NCEP2 accumulation does not correlate significantly for the raw data, and none of the estimates correlate significantly for the detrended case. Both NCEP2 and ERA-15-ECT appear to overestimate precipitation, considering the small sublimation and drift snow effects (Figs. 6 and 7) at this site, while the DRM estimates closely match the measured accumulation.

Figure 18 shows the interannual variations of modeled precipitation from the various methods and those of measured accumulation for 1993-99 at South Pole Station (Mosley-Thompson et al. 1999). The measured accumulation values shown in Fig. 18 are annual accumulation averages for the 236 snow stakes of the South Pole OSU 1992 Network. It is found that the interannual variability of modeled precipitation at the South Pole is not well represented by any of the methods. None of the estimates correlates significantly at the 95\% confidence level with the measured precipitation for the raw or the detrended time series (Table 3), although the correlations for DRM and ERA-15-ECT are 0.49 and 0.61 , respectively, for the raw time series. Due to the small sample size ( $7 \mathrm{yr}$ ), the data were also tested at the $90 \%$ confidence level; none of the correlations are significant at this level either. As noted in the previous section, precipitation in the interior of Antarctica is significantly underestimated by ECT, ERA-15, and
NCEP2 (Table 1). Compared to forecast precipitation from ECT, ERA-15, and NCEP2, DRM precipitation follows the measured annual mean accumulation more closely.

\section{c. Recent precipitation trends over the Antarctic ice sheets}

The interannual variations of the mean precipitation from various methods over all of Antarctica for the last two decades are shown in Fig. 13. The reasonable agreement among the three methods ( $r$ ranges from 0.43 to 0.60 ; Table 3 ) implies a validation of the upward trend of +1.3 to $+1.7 \mathrm{~mm} \mathrm{yr}^{-2}$ from 1979 to 1999 (Table 4), which is significant at the $95 \%$ confidence level for all three datasets. This upward trend is an agreement with other studies (e.g., Morgan et al. 1991; Bromwich and Robasky 1993; Mosley-Thompson et al. 1995), and is notable in view of the complex trends in Antarctic surface temperatures (Comiso 2000; Doran et al. 2002). Despite the reasonable agreement between the trends, overall it is noteworthy that there are temporal differences. The NCEP2 trend is almost consistently upward from 1982 to 1999. The ERA-15-ECT trend is indistinguishable before 1994, when it turns abruptly upward. The DRM trend occurs mainly due to a "step" between two precipitation plateaus that occurs in 199091; at this time ECT fields replace ERA-15 in the DRM calculations.

Because the use of a consistent data assimilation

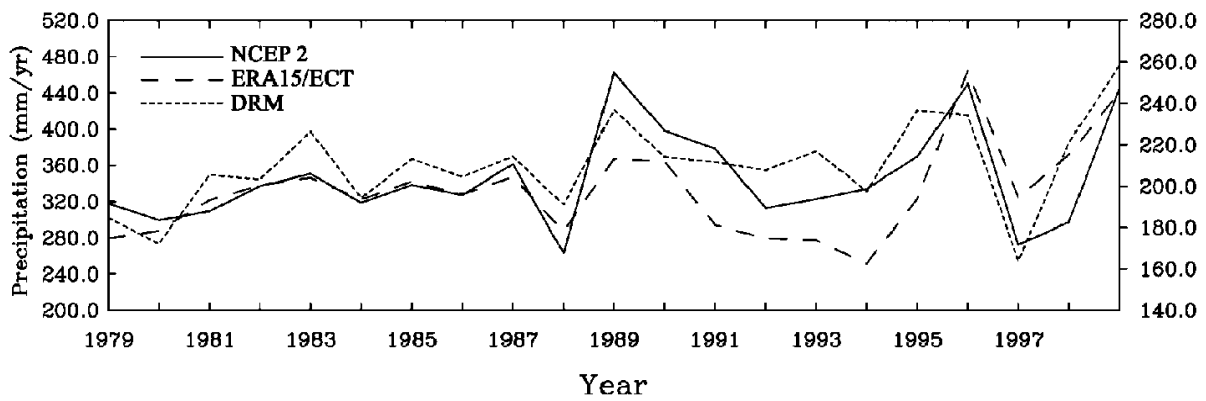

FIG. 16. Annual time series for the modeled precipitation over South Atlantic sector bounded by $65^{\circ}-75^{\circ} \mathrm{S}, 30^{\circ}-60^{\circ} \mathrm{W}$. Note that the right-hand scale is for DRM. 


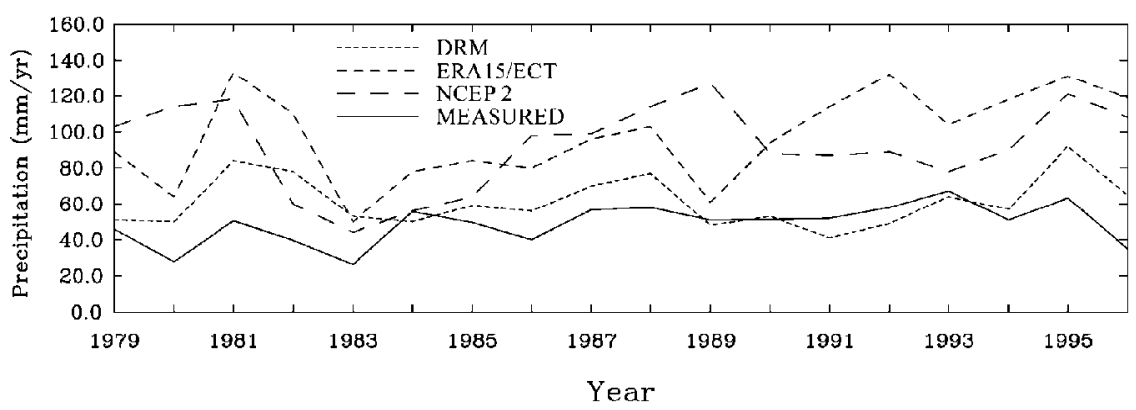

FIG. 17. The interannual variations of measured accumulation and modeled precipitation from various methods at the ice core site FB9815.

scheme helps avoid the artificial discontinuities of operational analyses, atmospheric reanalyses are particularly valuable for investigation of recent climate variability. Figures 19 and 20 show the spatial distribution of the linear trend from ERA-15 forecast precipitation and DRM precipitation with ERA-15. Although these two figures span the period 1979-93, they are thought to generally depict the sign and spatial distribution of the trends throughout the 1980s and 1990s. Similar spatial patterns are present in the linear trend of the DRM precipitation with ECT (1991-99), which is not shown here. Both increases and decreases can be found in recent precipitation rates over Antarctica. In general, there is reasonable agreement in the pattern of precipitation rate variation between these two figures. First, small changes in recent precipitation rate variations are found in the interior of Antarctica. A small increase in the recent precipitation rate around the South Pole is consistent with the results of Mosley-Thompson et al. (1999). Second, there are two areas that show significant increases: central West Antarctica and the area around Law Dome (near $\left.110^{\circ} \mathrm{E}\right)$. The recent increases in the precipitation rate around Law Dome are in agreement with previous findings from Morgan et al. (1991). Third, it is also found that the precipitation trend is weakly downward over much of the continental interior. This area, due to its high topography, is somewhat isolated from large synoptic systems in the Southern Ocean, and the implied increase in moisture fluxes toward Antarctica due to changes in the heat content of the Southern
Ocean (discussed below) may have less of an impact here. Additional ice cores should be used to test the validity of the precipitation trends over Antarctica, such as those being collected by the International Trans-Antarctic Scientific Expedition (ITASE).

The simulated precipitation increase for 1979-99 indicates that Antarctic precipitation removes an additional $\sim 0.05 \mathrm{~mm} \mathrm{yr}^{-1}$ from the global ocean. This offset is small in relation to the observed global sea level rise of $\sim 2 \mathrm{~mm} \mathrm{yr}^{-1}$ (e.g., Douglas and Peltier 2002). The precipitation increase is consistent with the positive trend in sea surface temperatures observed in the midlatitudes of the Southern Ocean over the latter half of the twentieth century (Casey and Cornillon 2001) that encompass the source region of Antarctic precipitation (Delaygue et al. 1999).

\section{Conclusions}

Atmospheric numerical simulation and dynamic retrieval method with atmospheric numerical analyses are used to assess the spatial and temporal variability of Antarctic precipitation for the last two decades. First, the Polar MM5, a version of the PSU-NCAR fifth-generation mesoscale model modified particularly for ice sheet applications has been run over Antarctica to study the Antarctic precipitation. With a horizontal resolution of $60 \mathrm{~km}$, the Polar MM5 has been run for the period of July 1996 through June 1999 in a series of shortterm forecasts from initial and boundary conditions pro-

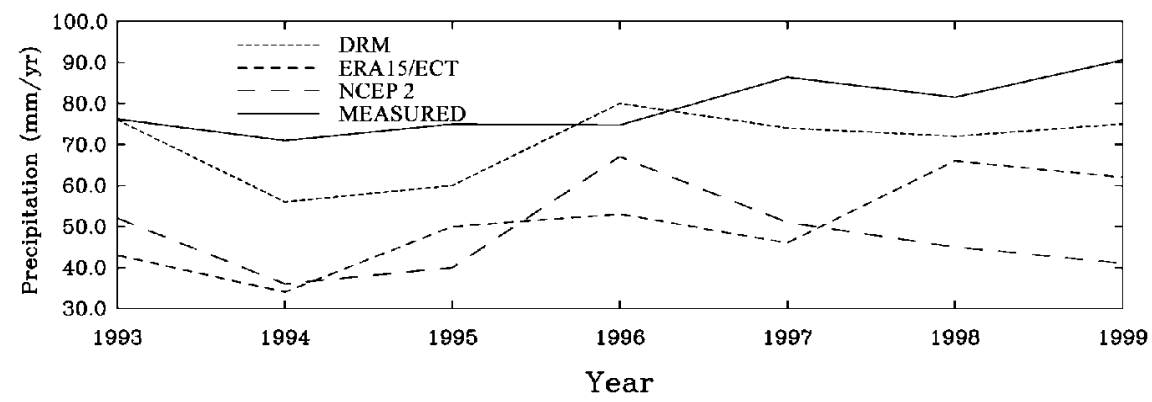

FIG. 18. The interannual variations of measured accumulation (from 236 snow stakes) and modeled precipitation from various methods at the South Pole. 


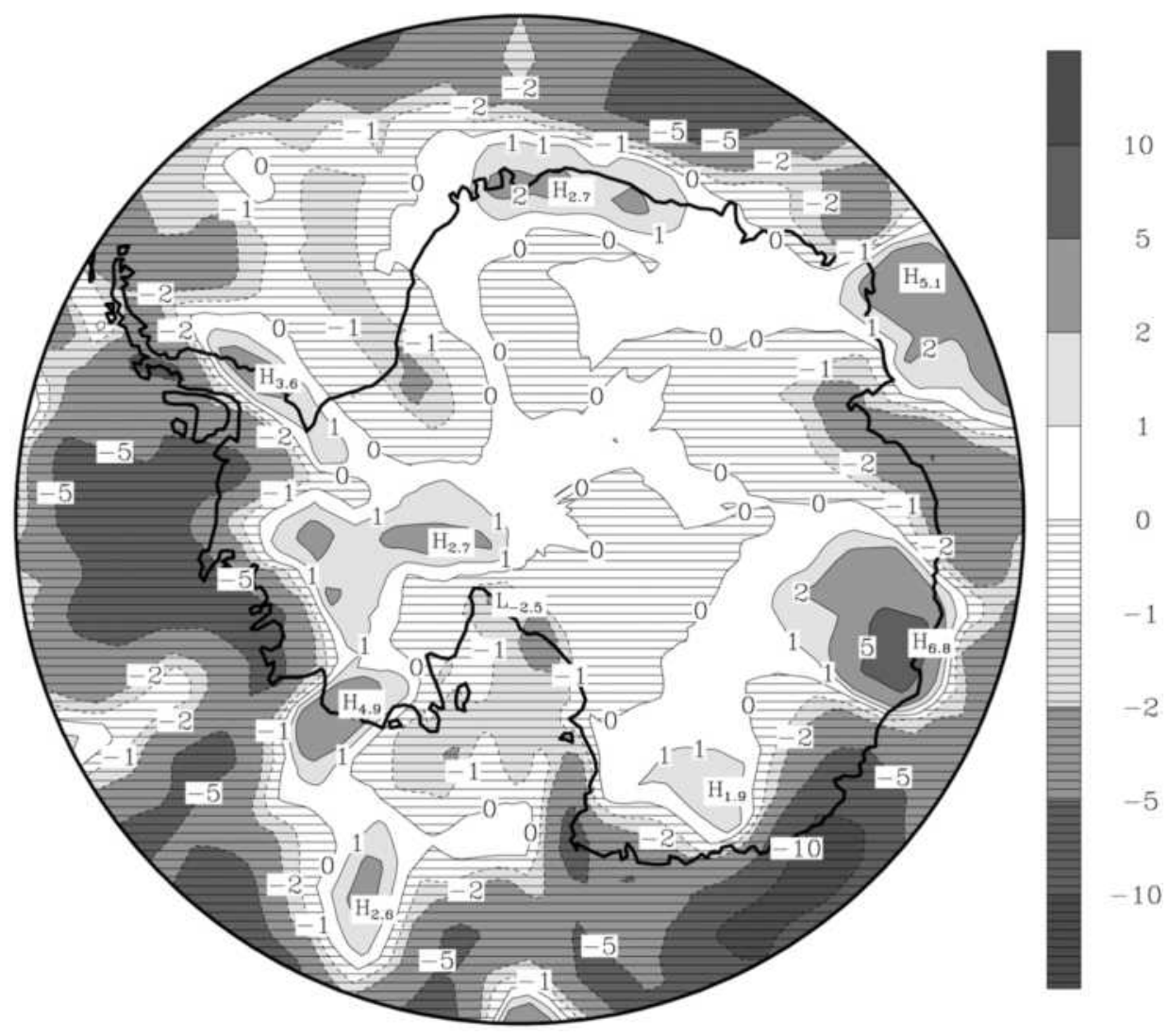

FIG. 19. Temporal trend of the linear regression line $\left(\mathrm{mm} \mathrm{yr}^{-2}\right.$ water equivalent) for the forecast precipitation from ERA-15 (1979-93).

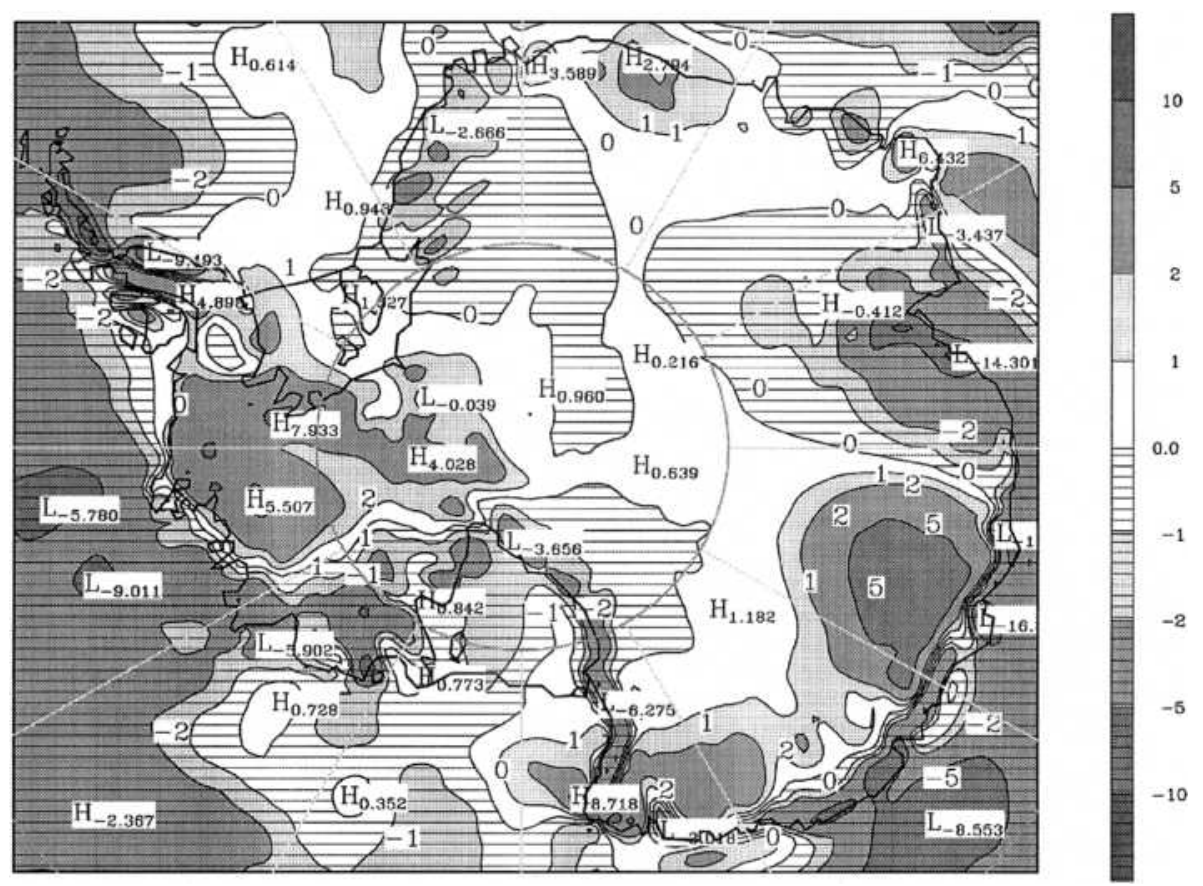

FIG. 20. Temporal trend of the linear regression line $\left(\mathrm{mm} \mathrm{yr}^{-2}\right.$ water equivalent) for the retrieved precipitation amount from the dynamic retrieval method with ERA-15 (1979-93). 
vided by the ECMWF operational analyses. In comparison with climatological maps, the major features of the spatial distribution of Antarctic precipitation are well captured by the Polar MM5. Drift snow effects on redistribution of surface accumulation over Antarctica are also assessed with surface wind fields from Polar MM5 in this study. There are complex divergence and convergence patterns of drift snow transport over Antarctica, especially along the coast. It is found that areas with large drift snow transport convergence and divergence are located around escarpment areas where there is large katabatic wind acceleration. In addition, areas with large snow transport divergence are generally accompanied by areas with large snow transport convergence nearby, indicating that drift snow transport is of local importance for the redistribution of the snowfall.

The precipitation for Antarctica from 1979 to 1999 has been retrieved by a vertical motion calculation using ECMWF operational analyses (ECT, 1985-99) and reanalysis (ERA-15, 1979-93). The dynamic retrieval method is applied to retrieve the precipitation over Antarctica from 1979 to 1999 in this study. In comparison with glaciological estimates and Polar MM5 simulations, most major features in the spatial distribution of Antarctic accumulation are well captured by the dynamic retrieval results. In comparison with predicted values from ERA-15 (1979-93), ECT (1991-99), and NCEPDOE AMIP-2 (NCEP2, 1979-99), dynamic retrieval calculations capture more mesoscale features of the precipitation distribution over Antarctica. In comparison with available ice core measurements from Dronning Maud Land the interannual variability of the Antarctic precipitation is reasonably represented by the dynamic retrieval results, having a significant correlation. However, in comparison with snow stake measurements from the South Pole the correlation is not significant. The DRM precipitation is quantitatively more accurate than the NCEP2 and ERA-15-ECT precipitation at both sites, following the measured accumulation more closely. A significant upward trend +1.3 to $+1.7 \mathrm{~mm} \mathrm{yr}^{-2}$ for 1979-99 is found from retrieved and forecast Antarctic precipitation that is consistent with results reported by other investigators. This indicates that additional water is being extracted from the global ocean and locked up in the Antarctic ice sheets, about $0.05 \mathrm{~mm} \mathrm{yr}^{-1}$. While there is good agreement in this trend between all of the datasets, the interannual variability about the trend is not well captured on the continental scale. However, on the subcontinental scale, the interannual variability about the trend is well resolved for sectors in West Antarctica and the South Atlantic. It is also noted that the precipitation trend is weakly downward over much of the continent.

Acknowledgments. This research was funded by National Science Foundation Grant OPP-9725730 and National Aeronautics and Space Administration Grant NAG5-11794 to D. H. Bromwich. The global ECMWF analyses were obtained from NCAR under Grant 3706880. The authors would like to thank the editor, Dr. Michael E. Mann, and three anonymous reviewers for their valuable comments.

\section{REFERENCES}

Aoki, S., and Coauthors, 1998: Preliminary investigation of palaeoclimate signals recorded in the ice core from Dome Fuji station, East Dronning Maud Land, Antarctica. Ann. Glaciol., 27, 338342.

Bintanja, R., and C. H. Reijmer, 2001: A simple parameterization for snowdrift sublimation over Antarctic snow surfaces. J. Geophys. Res., 106, 31 739-31748.

Bromwich, D. H., 1988: Snowfall in high southern latitudes. Rev. Geophys., 26, 149-168.

, 1990: Estimates of Antarctic precipitation. Nature, 343, 627629.

-, and F. M. Robasky, 1993: Recent precipitation trends over the polar ice sheets. Meteor. Atmos. Phys., 51, 259-274.

$\longrightarrow, \ldots$, R. A. Keen, and J. F. Bolzan, 1993: Modeled variations of precipitation over the Greenland ice sheet. J. Climate, $\mathbf{6}$, $1253-1268$.

- A. N. Rogers, P. Kallberg, R. I. Cullather, J. W. C. White, and K. J. Kreutz, 2000: ECMWF analyses and reanalyses depiction of ENSO signal in Antarctic precipitation. J. Climate, 13, 14061420.

_ J. J. Cassano, T. Klein, G. Heinemann, K. M. Hines, K. Steffen, and J. E. Box, 2001a: Mesoscale modeling of katabatic winds over Greenland with the Polar MM5. Mon. Wea. Rev., 129, 2290-2309.

—, Q.-S. Chen, L.-S. Bai, E. N. Cassano, and Y.-F. Li, 2001b: Modeled precipitation variability over the Greenland ice sheet. J. Geophys. Res., 106, 33 891-33908.

Budd, W. F., W. R. J. Dingle, and U. Radok, 1966: The Byrd snowdrift project: Outline and basic results. Studies in Antarctic Meteorology, M. J. Rubin, Ed., Antarctic Research Series, Vol. 9, Amer. Geophys. Union, 71-134.

Casey, K. S., and P. Cornillon, 2001: Global and regional sea surface temperature trends. J. Climate, 14, 3801-3818.

Cassano, J. J., J. E. Box, D. H. Bromwich, L. Li, and K. Steffen, 2001: Verification of Polar MM5 simulations of Greenland's atmospheric circulation. J. Geophys. Res., 106, 33 867-33 890.

Chen, Q.-S., and Y.-H. Kuo, 1992: A harmonic-sine series expansion and its application to the partitioning and reconstruction problem in a limited area. Mon. Wea. Rev., 120, 91-112.

- and D. H. Bromwich, 1999: An equivalent isobaric geopotential height and its application to synoptic analysis and a generalized $\omega$ equation in $\sigma$ coordinates. Mon. Wea. Rev., 127, 145-172.

$\longrightarrow$, - and D. H. Bromwich, 1996: A balanced ageostrophic initialization with a fixed external wind boundary value for limited-area models. J. Meteor. Soc. Japan, 74, 325-342.

_ L. Bai, and D. H. Bromwich, 1997a: A harmonic-Fourier spectral limited-area model with an external wind lateral boundary condition. Mon. Wea. Rev., 125, 143-167.

— D. H. Bromwich, and L. Bai, 1997b: Precipitation over Greenland retrieved by the dynamic method and its relation to cyclonic activity. J. Climate, 10, 839-870.

Colle, B. A., K. J. Westrick, and C. F. Mass, 1999: Evaluation of MM5 and Eta-10 precipitation forecasts over the Pacific Northwest during the cool season. Wea. Forecasting, 14, 137-154.

Comiso, J. C., 2000: Variability and trends in Antarctic surface temperatures from in situ and satellite infrared measurements. $J$. Climate, 13, 1674-1696.

Cullather, R. I., D. H. Bromwich, and M. L. van Woert, 1998: Spatial and temporal variability of Antarctic precipitation from atmospheric methods. J. Climate, 11, 334-367.

Delaygue, G., V. Masson, and J. Jouzel, 1999: Climatic stability of the geographic origin of Antarctic precipitation simulated by an 
atmospheric general circulation model. Ann. Glaciol., 29, 4548.

Doran, P. T., and Coauthors, 2002: Antarctic climate cooling and terrestrial ecosystem response. Nature, 415, 517-520.

Douglas, B. C., and W. R. Peltier, 2002: The puzzle of global sealevel rise. Phys. Today, 55, 35-40.

Drinkwater, M. R., D. G. Long, and A. W. Bingham, 2001: Greenland snow accumulation estimates from satellite radar scatterometer data. J. Geophys. Res., 106, 33 935-33950.

Dudhia, J., 1993: A nonhydrostatic version of the Penn State-NCAR mesoscale model: Validation tests and simulation of an Atlantic cyclone and cold front. Mon. Wea. Rev., 121, 1493-1513.

ECMWF, 1999: The description of the evolution of the ECMWF forecasting system and corresponding archive. ECMWF, Reading, United Kingdom, 122 pp.

Fletcher, N. H., 1962: Physics of Rain Clouds. Cambridge University Press, $386 \mathrm{pp}$.

Gallee, H., 1998: Simulation of blowing snow over the Antarctic ice sheet. Ann. Glaciol., 26, 203-206.

Genthon, C., and G. Krinner, 2001: Antarctic surface mass balance and systematic biases in general circulation models. J. Geophys. Res., 106, 20 653-20 664.

Giovinetto, M. B., and C. R. Bentley, 1985: Surface balance in ice drainage systems of Antarctica. Antarct. J. U.S., 20, 6-13.

Grell, G. L., J. Dudhia, and D. R. Stauffer, 1994: A description of the fifth-generation Penn State/NCAR Mesoscale Model (MM5) NCAR Tech. Note NCAR/TN-398 + STR, 122 pp.

Guo, Z., 2002: Spatial and temporal variability of modern Antarctic precipitation. Ph.D. dissertation, The Ohio State University, 150 pp.

, D. H. Bromwich, and J. J. Cassano, 2003: Evaluation of Polar MM5 simulations of Antarctic atmospheric circulation. Mon. Wea. Rev., 131, 384-411.

,-- , and K. M. Hines, 2004: Modeled Antarctic precipitation. Part II: ENSO modulation over West Antarctica. J. Climate, 17, 448-465.

Hack, J. J., B. A. Boville, B. P. Briegleb, J. T. Kiehl, P. J. Rasch, and D. L. Williamson, 1993: Description of the NCAR community climate model (CCM2). NCAR Tech. Note NCAR/TN-382 + STR, 108 pp.

Haltiner, G. J., and R. T. Williams, 1980: Numerical Prediction and Dynamical Meteorology. John Wiley and Sons, $477 \mathrm{pp}$.

Herron, M. M., 1982: Impurity sources of $\mathrm{F}^{-}, \mathrm{Cl}^{-}, \mathrm{NO}_{3}^{-}$, and $\mathrm{SO}_{4}^{2-}$ in Greenland and Antarctic precipitation. J. Geophys. Res., 87, 3052-3060.

Hines, K. M., D. H. Bromwich, and Z. Liu, 1997: Combined global climate model and mesoscale model simulations of Antarctic climate. J. Geophys. Res., 102, 13 747-13 760.

,-- , and G. J. Marshall, 2000: Artificial surface pressure trends in the NCEP-NCAR reanalysis over the Southern Ocean and Antarctica. J. Climate, 13, 3940-3952.

Janjić, Z. I., 1994: The step-mountain eta coordinate model: Further developments of the convection, viscous sublayer, and turbulence closure schemes. Mon. Wea. Rev., 122, 927-945.

Legrand, M., and R. J. Delmas, 1987: A 220-year continuous record of Volcanic $\mathrm{H}_{2} \mathrm{SO}_{4}$ in the Antarctic ice sheet. Nature, 327, 671676.

Liu, H., K. C. Jezek, and B. Li, 1999: Development of an Antarctic digital elevation model by integrating cartographic and remotely sensed data: A geographic information system based approach. J. Geophys. Res., 104, 23 199-23 213.

Meyers, M. P., P. J. DeMott, and W. R. Cotton, 1992: New primary ice-nucleation parameterizations in an explicit cloud model. $J$. Appl. Meteor., 31, 708-721.

Morgan, V. I., I. D. Goodwin, D. M. Etheridge, and C. W. Wookey, 1991: Evidence from Antarctic ice cores for recent increases in snow accumulation. Nature, 354, 58-60.

Mosley-Thompson, E., L. G. Thompson, J. F. Paskievitch, M. Pourchet, A. J. Gow, M. E. Davis, and J. Kleinman, 1995: Recent increase in South Pole snow accumulation. Ann. Glaciol., 21, 131-138.

_ - J. F. Paskievitch, A. J. Gow, and L. G. Thomspon, 1999: Late 20th century increase in South Pole snow accumulation. J. Geophys. Res., 104, 3877-3886.

Oerter, H., F. Wilhelms, F. Jung-Rothenhäusler, F. Göktas, H. Miller, W. Graf, and S. Sommer, 2000: Accumulation rates in Dronning Maud Land, Antarctica, as revealed by dielectric-profiling measurements of shallow firn cores. Ann. Glaciol., 30, 27-34.

Ohmura, A., M. A. Wild, and L. Bengtsson, 1996: A possible change in mass balance of Greenland and Antarctic ice sheets in the coming century. J. Climate, 9, 2124-2135.

Pauley, P. M., and S. J. Nieman, 1992: A comparison of quasigeostrophic and nonquasigeostrophic vertical motions for a rapidly intensifying marine extratropical cyclone. Mon. Wea. Rev., 120, 1108-1134.

Petit, J. R., J. Jouzel, M. Pourchet, and L. Merlivat, 1982: A detailed study of snow accumulation and stable isotope content in Dome C (Antarctica). J. Geophys. Res., 87 (C6), 4301-4308.

Reijmer, C. H., M. R. van den Broeke, and M. P. Scheele, 2002: Air parcel trajectories and snowfall related to five deep drilling locations in Antarctica based on the ERA-15 dataset. J. Climate, 15, 1957-1968.

Reisner, J., R. M. Rasmussen, and R. T. Bruintjes, 1998: Explicit forecasting of supercooled liquid water in winter storms using the MM5 mesoscale model. Quart. J. Roy. Meteor. Soc., 124, 1071-1107.

Sinclair, M. R., 1994: A diagnostic model for estimating orographic precipitation. J. Appl. Meteor., 33, 1163-1175.

Turner, J., W. M. Connolley, S. Leonard, G. J. Marshall, and D. G. Vaughan, 1999: Spatial and temporal variability of net snow accumulation over the Antarctic from ECMWF re-analysis project data. Int. J. Climatol., 19, 697-724.

van den Broeke, M. R., 1997: Spatial and temporal variation of sublimation on Antarctica: Results of a high-resolution general circulation model. J. Geophys. Res., 102, 29 765-29 777.

Vaughan, D. G., J. L. Bamber, M. Giovinetto, J. Russell, and A. P. R. Cooper, 1999: Reassessment of net surface mass balance in Antarctica. J. Climate, 12, 933-946.

Winebrenner, D. P., R. J. Arthern, and C. A. Shuman, 2001: Mapping Greenland accumulation rates using observations of thermal emission at 4.5-cm wavelength. J. Geophys. Res., 106, 33 91933934.

Wingham, D. J., A. J. Ridout, R. Scharroo, R. J. Arthern, and C. K. Shum, 1998: Antarctic elevation change from 1992-1996. Science, 282, 456-458.

Xie, P. P., and P. A. Arkin, 1998: Global monthly precipitation estimates from satellite-observed outgoing longwave radiation. $J$. Climate, 11, 137-164.

Yen, Y. C., 1981: Review of thermal properties of snow, ice and sea ice. U.S. Army Cold Regions Research and Engineering Laboratory, CRREL Rep. 81-10, 27 pp. 